\title{
The crystallinity and thermal degradation behaviour of polyamide 6/oil based mud fillers (PA6/OBMFs) nanocomposites.
}

\author{
SIDDIQUE, S., KWOFFIE, L., ADDAE-AFOAKWA, K., YATES, K., \\ NJUGUNA, J.
}




\section{Accepted Manuscript}

The crystallinity and thermal degradation behaviour of polyamide 6/Oil Based Mud

Fillers (PA6/OBMFs) nanocomposites

Shohel Siddique, Lorraine Kwoffie, Kofi Addae-Afoakwa, Kyari Yates, James Njuguna

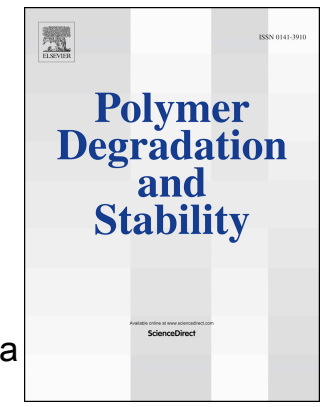

PII:

S0141-3910(18)30354-9

DOI: https://doi.org/10.1016/j.polymdegradstab.2018.11.004

Reference: $\quad$ PDST 8682

To appear in: Polymer Degradation and Stability

Received Date: 2 January 2018

Revised Date: 16 October 2018

Accepted Date: 5 November 2018

Please cite this article as: Siddique S, Kwoffie L, Addae-Afoakwa K, Yates K, Njuguna J, The crystallinity and thermal degradation behaviour of polyamide 6/Oil Based Mud Fillers (PA6/ OBMFs) nanocomposites, Polymer Degradation and Stability (2018), doi: https://doi.org/10.1016/ j.polymdegradstab.2018.11.004.

This is a PDF file of an unedited manuscript that has been accepted for publication. As a service to our customers we are providing this early version of the manuscript. The manuscript will undergo copyediting, typesetting, and review of the resulting proof before it is published in its final form. Please note that during the production process errors may be discovered which could affect the content, and all legal disclaimers that apply to the journal pertain. 
The Crystallinity and Thermal Degradation Behaviour of Polyamide 6/Oil

\section{Based Mud Fillers (PA6/OBMFs) nanocomposites}

Shohel Siddique ${ }^{1}$, Lorraine Kwoffie ${ }^{1}$, Kofi Addae-Afoakwa ${ }^{1}$, Kyari Yates ${ }^{2}$ and James Njuguna ${ }^{1 *}$

${ }^{1}$ School of Engineering, Robert Gordon University, Riverside East, Garthdee Road, Aberdeen, AB10 7GJ, UK

${ }^{2}$ School of Pharmacy and Life Sciences, Robert Gordon University, Aberdeen, AB10 7GJ, UK

"Corresponding Author Email : j.njuguna@rgu.ac.uk; Tel. +44 (0) 1224262304

\section{Abstract:}

The crystallinity and thermal degradation behaviours of Polyamide 6/Oil Based Mud Fillers (PA6/OBMFs) nanocomposites have been investigated using DSC and TGA. TGA indicates the onset decomposition temperature of D1/2 (half-decomposition) is $16^{\circ} \mathrm{C}$ higher for PA6 with 10.0 wt.\% of OBMFs than that of PA6, whereas the lowest onset decomposition temperature difference among the nanocomposites and neat PA6 is $8^{\circ} \mathrm{C}$ for PA6 with 7.5 wt.\% of OBMFs. However PA6 with 5.0 wt. \% OBMFs nanocomposite has taken the longest time (1minute 36 seconds more than neat PA6) to reach D1/2. It can be deduced in this study that PA6 with 5.0 wt. \% OBMFs nanocomposite provided the maximum heat resistant property whereas PA6 with 7.5 wt. \% OBMFs nanocomposite showed the maximum heat absorbance property among different nanocomposites and PA6 with 10.0 wt. 
$\%$ exhibited the maximum thermal stability. There is a sigmoidal curve generated based on the TIF and wt\% filler content value which shows three significant points at intersections of $50 \%$ TIF line which are highlighted as exfoliation (4.2 wt.\%), intercalation (6.8 wt.\%) and agglomeration (9.0 wt.\%) points. These TIF values explained the investigated heat resistant, heat capacity and thermal stability properties of PA6/OBMFs nanocomposites illustrating the ratio of TIF and MAF is the key measure which can be considered as an effective approach to identify the nanomorphology of PA6/OBMFs nanocomposites.

Keywords: Polyamide 6; Nanocomposite; Thermal degradation; Crystallinity; Rigid amorphous fraction; Mobile amorphous fraction

\section{Introduction}

The application of layered aluminosilicate as fillers in polyamide nanocomposites has received attention in recent years. PA6- layered-silicates have been studied over years due to its unique properties to reduce flammability, increasing heat resistance, exhibit higher tensile strength, improving tensile modulus, increasing flexural strength and also improving flexural modulus [1-5]. The continuous improvement of these achievements has attracted researchers to scale up certain properties such as thermal stability, flame retardancy, ablation and barrier resistance in the composite material to increase the application of this material as advanced structural material in different industries including automotive and space industries [6-9]. 
The advancement of these properties largely depends upon the nanomorphology of this filler into the polymer chain as this morphology related to the chemical structure of the filler which is source of origin and surface modification dependent [10] [11].

However the source of clay minerals play an important role in influencing properties in nanocomposite materials [12] [13]. Considering the different aspects of clay mineral sources and potential applications in influencing the mechanical and thermal properties in nanocomposite materials, The Centre for Advanced Engineering Materials at Robert Gordon University has initiated an investigation on how the reclaimed layered silicate from oil based mud (OBM) waste influence the properties in engineering nanocomposite materials. It is also important to mention here that this research group has aimed to investigate the relation between the change in amorphosity and crystallinity of polymer chain due to the addition of these OBMFs in nanocomposite and the variation in properties of material mainly thermal property of material. These OBMFs behave in a similar manner as other inorganic particles which often act as nucleating agents in polymer nanocomposites and sometimes causes the retardation of crystallisation in the structure. Since the large surface of the nanofiller is contributing the greater interphases between filler and polymer matrix, it is believed that the properties of the materials are significantly influenced by this interaction between interphases [14]. In semicrystalline polymers such as PA6, two interphases which act as immobilised fraction are highlighted. One is present between the amorphous fraction and crystal fraction in the polymer and the other exists between the inorganic filler and polymer matrix. These 
interphases generate Rigid Amorphous Fraction (RAF) which act between crystal and amorphous phase as a result of evolving immobilisation of a polyamide chain due to crystal [15] [16]. The addition of clay particles in the PA6 nanocomposites can increases the growth rate of these crystals ( $\alpha$ or $y$ form). However increasing the clay content beyond a certain level retards the rate of crystallisation which plays the main role of in thermodynamic stability of the material [1] [17].

Although it is clearly evident that clay/nanoclay improves the mechanical and thermal properties of PA6/clay nanocomposite materials [18] [19], but there is no information available in literature on the influence of recovered nanoclay from OBM waste on the mechanical and thermal properties of composite materials. Investigations have been carried out in this study to determine the effects of OBMFs on thermal properties in PA6/OBMFs nanocomposites. As part of these investigations different analysis have been undertaken including Scanning Electron Microscopy (SEM), Fourier Transform infra-red (FTIR) spectroscopy, energy dispersive x-ray analysis (EDXA), Thermo-Gravimetric Analysis (TGA) and Differential Scanning Calorimetry (DSC) to determine morphological and chemical structure changes, thermal degradation and decomposition behaviour of materials. Additionally the changes in amorphous and crystal fractions have been discussed in this paper.

\section{Experimental}

\subsection{Materials}


Tarnamid $^{\circledR}$ T27 (trade name of PA6) polymer was supplied by Grupa Azoty, Poland. It has melting point of $250^{\circ} \mathrm{C}$ and a V-2 rating in UL94 (vertical burning test) at $1.6 \mathrm{~mm}$ thickness. Prior to melt compounding, PA6 was dried at $90^{\circ} \mathrm{C}$ for 24 hours in a convection oven. The spent oil based mud was donated by a local oil and gas company. Melt mixing of different wt. \% concentrations of Oil Based Mud Fillers (OBMFs) with PA6 was carried out using TwinTech Extrusion Itd LTD $10 \mathrm{~mm}$ twin screw extruder at $40 \mathrm{rpm}$ under the following test conditions $1^{\text {st }}$ zone $\left(190^{\circ} \mathrm{C}\right), 2^{\text {nd }}$ zone $\left(250^{\circ} \mathrm{C}\right), 3^{\text {rd }}$ zone $\left(240^{\circ} \mathrm{C}\right), 4^{\text {th }}$ zone $\left(210^{\circ} \mathrm{C}\right)$ and die $/ 5^{\text {th }}$ zone $\left(210^{\circ} \mathrm{C}\right)$. The granulated material was injection moulded into bar mould (dual cavity) for different analysis using temperature at $270^{\circ} \mathrm{C}$ with moulding pressure of 10 bar. The OBMFs preparation process is described in the following section. Montmorillonite, K10 powder obtained from Sigma-Aldrich, UK was used as a reference material to compare XRD pattern of OBMFs.

\subsection{OBMFs manufacturing process}

In filler processing, spent drilling fluid is heated sporadically to dry the fluid and eliminate total petroleum hydrocarbon (TPH) as much as possible. The mud is firstly heated at $50^{\circ} \mathrm{C}$ for 12 hours after which the temperature is increased to $80^{\circ} \mathrm{C}$ for a further 12 hours. This pre heating process is applied to avoid any potential fire hazards by vaporising the volatile organic contents associated with the fluid. This process is also further facilitated by decanting the oil-water mixture floating on the top of solid content. In the second stage, 
the furnace temperature is increased to $700^{\circ} \mathrm{C}$ and held at this temperature for 12 hours. Since the aim of this project is to use recovered solid content from spent oil based drilling fluid to manufacture flame retardant nanocomposite materials, the total elimination of base oil and volatile chemical contents is ignored. After recovering the solid content from spent drilling fluid, the next operation involved is reducing the particle size to nanoscale level to be used as a nanofiller in nanocomposite materials using a milling process.

Initially, large pieces of mud were crushed into smaller pieces using a grinder. This was followed by a further size reduction of the particles to produce fillers in powdered form using an IKA UltraTurrax ball mill.

\subsection{PA6/OBMFs nanocomposite manufacturing process}

In manufacturing nanocomposites using fillers recovered from spent drilling fluid, a commercially available polyamide 6 (PA6) is used. In this study, PA6 and recovered OBMFs is used in different concentrations. The filler concentrations used in this study are 2.5 wt. \%, 5.0 wt. \%, 7.5 wt. \% and 10.0 wt. \%.

The aim of this study is to identify how the thermal degradation behaviour of nanocomposite materials varies with the variant concentration of OBMFs present in materials. The temperature and pressure are $270^{\circ} \mathrm{C}$ and 10.0 bar respectively in manufacturing these nanocomposite samples using Gallomb Inc. USA injection moulder. The samples are then left to cool to room temperature before different analysis and characterisation processes.

\subsection{Characterisation}


To observe the morphology of OBMFs and its dispersion in polymer matrix, samples were broken into small pieces using liquid $\mathrm{N}_{2}$. The sections were observed using a Zeiss EVO LS10 Scanning Electron Microscope (SEM) with a magnification of $4000 \mathrm{X}, 4.5 \mathrm{~mm}$ working distance (WD) and accelerating potential of $25.00 \mathrm{kV}$. To minimise the sample being altered all the samples are gold coated using sputter deposition for 2 minutes prior to the experiment. To determine the composition of samples, energy dispersive $\mathrm{x}$-ray analysis (EDXA) (Oxford Instruments INCA Energy) was carried out. Optical microscopy was used to analyse the fracture surfaces of the samples whilst the cryo-fractured surface morphologies and the associated failure mechanisms were analysed using SEM and EDXA.

Attenuated Total Reflectance- Fourier Transform Infra-Red spectroscopy was carried out using a Thermo Scientific Nicolet iS10 FTIR Spectrometer. The spectrometer was set for 32 scans between $4000-400 \mathrm{~cm}^{-1}$ with a resolution of $4 \mathrm{~cm}^{-1}$. A blank measurement was also undertaken to minimise the influence of water vapour and carbon dioxide from the atmosphere.

Thermo-Gravimetric Analysis (TGA) was carried out using a TA TGA Q500 instrument to determine the degradation and decomposition temperature as well as the rate of degradation of the nanocomposite samples.

This analysis is performed by measuring the weight variation of a given sample due to temperature increase and phase change as the sample degrades until it is decomposed. TGA instrument used is TA instrument TGA Q500. The temperature was set on ramp mode from room temperature (20 $\left.{ }^{\circ} \mathrm{C}\right)$ to $1000{ }^{\circ} \mathrm{C}$ at a rate of $10^{\circ} \mathrm{C}$ per minute. Differential Scanning Calorimetry 
(DSC) analysis was performed with a TA Q100 instrument under a nitrogen environment to ascertain the melting temperatures, crystallisation temperatures as well as the glass transition temperatures of the materials. The instrument measures the difference in heat exchange between the sample and the reference (an empty aluminium pan). The temperature was set on heat/cool/heat procedure or mode from a temperature of $-20 \stackrel{\circ}{\mathrm{C}}$ to 250 ${ }^{\circ} \mathrm{C}$ at a rate of $10{ }^{\circ} \mathrm{C}$ per minute.- In addition X-ray Diffraction (XRD) data were collected in the range $3-60^{\circ}$ using a Siemens D5000 diffractometer with Cu Ka radiation $(\lambda=0.15406 \mathrm{~nm}), 0.1^{\circ} 2 \theta$ step size and a $6 \mathrm{~s}$ count time per step with a $0.066^{\circ}$ slit width. Furthermore, TEM images of PA6/OBMFs nanocomposites were obtained at $80 \mathrm{kV}$, using the Titan Themis 200 scanning transmission electron microscope (S/TEM). In order to prepare TEM samples, small sections of the injection moulded samples were embedded in epoxy resin and cured in histology cassettes overnight at room temperature. Finally, thin sections were cut using Leica microtome and deposited on copper grids.

\section{Results and discussion}

\subsection{ATR-FTIR analysis of materials}

The resulting spectra from the ATR-FTIR analysis of the PA6 and PA6/OBMFs nanocomposites is presented in Figure 1.

[Fig. 1:] 
Review to individual spectra are provided in Supporting Information (Fig. S1) and a summary of ATR-FTIR peak assignments presented in Table 1 based on literature [20-23].

\section{[Table 1:]}

The presence of band peak at $3294-3296 \mathrm{~cm}^{-1}$ for all samples, it is evident that nearly $100 \%$ hydrogen bonding in linear aliphatic homopolyamides at room temperature. Since the transmittance coefficients of the band at 3295 $\mathrm{cm}^{-1}$ for the five specimens are different, then the strength of hydrogen bonds among these five samples are not comparable. However the wavenumbers of these five samples are similar representing the OBMFs had little effect on the average strength of hydrogen bonding.

It is interesting that this FTIR spectra is applicable effectively to qualitatively analyse the crystallinity phase changes (e.g. amorphous phase to crystal phase or $y$ form to $\alpha$ form). To investigate the amorphous and both $\alpha$ and $y$ crystalline phases in this study, certain band assignments positions are important. The band at $1118 \mathrm{~cm}^{-1}$ is attributed as the amorphous phase whereas the band at $973 \mathrm{~cm}^{-1}$ is attributed as the $\mathrm{V}$ phase crystal form. In addition the band at $930 \mathrm{~cm}^{-1}$ and $1200 \mathrm{~cm}^{-1}$ are attributed as $\alpha$ phase crystal form [20] [23].

[Fig. 2] 
Fig. 2 shows a magnified comparison of ATR-FTIR spectra for the studied materials between $1200-525 \mathrm{~cm}^{-1}$.

In this study, there is a band at $1200 \mathrm{~cm}^{-1}$ for neat PA6 and its nanocomposite, showing the strong a form although the band at $930 \mathrm{~cm}^{-1}$ is very weak for all the samples. However, the $\mathrm{y}$ crystalline phase is noticeable at band $973 \mathrm{~cm}^{-1}$ in neat PA6 with 7.5 wt.\% OBMFs and PA6 with 10.0 wt.\% OBMFs nanocomposites whereas this phase is very weak for other nanocomposites. It is attributed here that this influencing $\mathrm{y}$ crystalline phase contributes the incremental \% of crystallinity for neat PA6 with 7.5 wt. \% OBMFs and PA6 with 10.0 wt. \% OBMFs nanocomposites than the \% of crystallinity of PA6 with 2.5 wt. \% and 5.00 wt. \% OBMFs nanocomposites. This is agreed with the \% of crystallinity results presented in Table 3.

Investigating the spectrum for individual material in Fig. S1 (in supplementary information), it can be highlighted that the bands at $1169 \mathrm{~cm}^{-1}$, $1118 \mathrm{~cm}^{-1}$ and $1074 \mathrm{~cm}^{-1}$ represents the amorphous phase. The intensity of bands at $1169 \mathrm{~cm}^{-1}$ and $1118 \mathrm{~cm}^{-1}$ is similar for neat PA6 and PA6 with 2.5 wt.\% OBMFs materials whereas the intensity of these bands are stronger for PA6 with 5.0 wt.\% OBMFs and PA6 with 7.5 wt.\% OBMFs materials. However PA6 with 10.0 wt. \% OBMFs shows a weaker intensity in this amorphous bands compare to PA6 with 5.0 wt. \% OBMFs and PA6 with 7.5 wt. \% OBMFs materials. It is important to mention here that there is another additional band at $1074 \mathrm{~cm}^{-1}$ in PA6 with 7.5 wt. \% OBMFs spectra which is characterised as amorphous phase. Only PA6 with 7.5 wt. \% OBMFs material shows strongest intensity and subtle peaks at these three $1169 \mathrm{~cm}^{-1}, 1118 \mathrm{~cm}^{-1}$ and $1074 \mathrm{~cm}^{-1}$ amorphous bands which is also agreed with the superior heat capacity value 
for PA6 nanocomposite materials from DSC results presented in Table 4. Identifying the intensity and frequency nature of these materials, it can be attributed that the band at $1169 \mathrm{~cm}^{-1}$ represents the Mobile Amorphous Fraction (MAF) and the bands at $1118 \mathrm{~cm}^{-1}$ and $1074 \mathrm{~cm}^{-1}$ represents the Rigid Amorphous Fraction (RAF).

\subsection{Morphology of OBMFs and polyamide/OBMFs nanocomposite materials}

Morphological studies are carried out to understand the surface topography and composition of the specimen. A visual inspection of the thermally treated OBM sample (Fig. S2; Supplementary Information) and subsequent SEM image (Fig. S3; Supplementary Information) suggests perforation at the surface of the OBM sample which is attributed to the formation of bubbles as a consequence of the vaporisation of volatile organic compounds during the heating stage.

In Fig. S3, the micrograph of treated/untreated OBMFs clearly shows the presence of tightly stacked spherical particles with size ranges up to $1000 \mathrm{~nm}$.

[Fig. 3:]

The SEM micrographs were used to investigate the effect of OBMFs on the morphology of PA6 and its nanocomposite. Fig. 3(a) shows morphology of montmorillonite as a reference clay mineral to compare to the morphology of OBMFs which is presented in Fig. 3(b). Both 3(a) and 3(b) illustrate the shape and size of the clay platelets which is in nanoscale. Fig. 3(c) shows some 
cavitation and uneven surfaces for the fractured PA6 structures. The SEM micrograph of the composite made with $2.5 \mathrm{wt}$ \% filler (OBMFs) shows dispersed (unsaturated) OBMFs into PA6 matrix and also these particles are scattered over the PA6 matrix which is also noticeable in Fig. 3(d). The well dispersed OBMFs in PA6 matrix is clearly visible in Fig. 3(e). It can be articulated from the investigation of the geometrical structure of the particles that mostly exfoliation occurs in this nanocomposite. Figure $3(f)$ shows a clustering of small particles which is suggested to be the intercalation between PA6 and layered silicates and also an agglomeration of particles. An uneven and poor dispersion of OBMFs into the PA6 polymer matrix with a noticeable (Fig. 3(g)) agglomeration of particles is observed.

\subsection{Elemental Composition}

To determine the elemental composition and elucidate the effect of filler interactions with the PA6 matrix at varying filler compositions, Energy Dispersive X-ray (EDX) analysis was carried out as shown in Fig. 4a-e.

[Fig. 4:]

In Fig. 4(a) (b) (c) (d) (e) and (f) shows the EDX spectra and also the elemental profile (atomic wt \%) of OBMFs, neat PA6, PA6 with 2.5 wt. \% OBMFs, PA6 with 5.0 wt. \% OBMFs, PA6 with 7.5 wt. \% OBMFs and PA6 with 10.0 wt. \% OBMFs nanocomposites respectively. The spectra location of the respective parts designated in the Fig. $\mathbf{S} 4$ in supplementary information. 
In this figure, the horizontal axis represents the energy in keV and vertical axis represents the intensity counts of the X-ray.

As the filler content in the nanocomposites increases, there is an apparent increase in intensity and presence of other elements such as barium $(\mathrm{Ba})$, silicon ( $\mathrm{Si})$, sulphur $(\mathrm{S})$, iron $(\mathrm{Fe})$, sodium $(\mathrm{Na})$ and aluminium (Al). The presence of zinc $(\mathrm{Zn})$ is noticeable only in PA6 with $7.5 \mathrm{wt}$. \% nanocomposite sample. The intensity of $\mathrm{C}$ and oxygen $(\mathrm{O})$ increase significantly with the addition of filler in nanocomposite as shown in Fig. 4. It can inferred here that the incremental intensity of $\mathrm{C}$ and $\mathrm{O}$ and also the presence of other elements are originated from the OBMFs which has been used in manufacturing this nanocomposite.

Analysis of the EDX spectra for PA6 and its nanocomposites as shown in Fig.4, indicates a high wt. \% of barium (Ba) is present in the sample. This is probably a reflection of the large quantities of barium sulphate $\left(\mathrm{BaSO}_{4}\right)$ as weighting agent used in the formulation of the drilling fluid. The presence of silicon ( $\mathrm{Si})$ and oxygen $(\mathrm{O})$ peaks is expected due to the silicate matrix known to be present in bentonite clays. The incremental intensity of Carbon (C) peaks implies limestone $\left(\mathrm{CaCO}_{3}\right)$ may have been used as an additive in the drilling fluid to control circulation loss amongst other functions whereas the sulphur $(\mathrm{S})$ and iron $(\mathrm{Fe})$ peaks could be from iron sulfide $\left(\mathrm{FeS}_{2}\right)$ resulting from the use of iron oxide $\left(\mathrm{Fe}_{3} \mathrm{O}_{4}\right)$ usually used as an additive for scavenging hydrogen sulfide $\left(\mathrm{H}_{2} \mathrm{~S}\right)$. Also, peaks of chlorine from the analysis are an indication that chloride salts $(\mathrm{NaCl}$ or $\mathrm{KCl})$ may have been used as an electrolyte. Finally, the calcium (Ca), potassium (K), aluminium (Al) and sodium $(\mathrm{Na})$ peaks may be characteristic of the ion exchange surface of the 
clay or the minerals associated with the clay reclaimed from drilling fluid waste.

\subsection{Thermogravimetric analysis (TGA)}

The thermal degradation of PA6/OBMFs nanocomposite has been analysed in $\mathrm{N}_{2}$ environment using TA instrument TGA Q500. Weight loss curves of the samples in different stages are given in Fig. 5.

\section{[Fig. 5:]}

In addition Table 2 shows the degradation at different stages such as at $250{ }^{\circ} \mathrm{C}$, temperature and time at $\mathrm{D} 1 / 2$ (50\% weight loss) and the residue at $600{ }^{\circ} \mathrm{C}$. Although the analysis temperature has been selected from room temperature $\left(20^{\circ} \mathrm{C}\right)$ to $1000^{\circ} \mathrm{C}$ at $10{ }^{\circ} \mathrm{C} /$ minute rate, there was not any significant changes in decomposition curve noticeable in the Fig. 5 after 600 ${ }^{\circ} \mathrm{C}$. However the neat PA6 shows the lowest thermal stability among the samples. The degradation trends for all the samples were similar until the temperature reached to $300^{\circ} \mathrm{C}$. Between $350{ }^{\circ} \mathrm{C}$ to $450{ }^{\circ} \mathrm{C}$ temperature, PA6 decomposed distinctly faster than any other samples. This is the temperature range when maximum weight has been lost in PA6 and its nanocomposite samples. However the onset decomposition of PA6 starts at $300^{\circ} \mathrm{C}$ whereas the onset decomposition of other samples starts at $420^{\circ} \mathrm{C}$. This indicated that PA6/OBMFs nanocomposites had greater thermal stability than neat PA6. 
[Table 2:]

Investigating D1/2 for PA6 and its nanocomposite, it is clearly noticeable that PA6 with 5.0 wt. \% OBMFs nanocomposite took the longest time (42.42 $\min$ ) to reach $\mathrm{D} 1 / 2$ that is related to the flame retardancy property of polymeric material and it is believed this result is a consequence of combined effects of clay dispersion and confinement of polyamide chains in the interlayers of clay platelets. This is in a good agreement with the morphological observations in Fig. 3 (c) which indicated exfoliated structure for PA6 with 5.0 wt. \% OBMFs nanocomposite. However PA6 with 10.0 wt. \% OBMFs showed the highest temperature $\left(447.35^{\circ} \mathrm{C}\right)$ at D1/2 which indicated the best thermal stability among the samples. In addition, the onset degradation temperature in both $10 \%$ and $50 \%$ weight loss cases showed the thermal stability trend as: PA6 + $10.0 \mathrm{wt} \%$ OBMFs>PA6+5.0 wt $\%$ OBMFs>PA6+2.5 wt\% OBMFs/PA6+ 7.5 wt\% OBMFs>PA6. This findings also agree with the results obtained from heat capacity in Table 4 which suggested PA6 with $7.5 \mathrm{wt} \%$ showed the maximum heat capacity property. It is assumed the excess energy is stored by nanocomposite during the solidliquid phase change process.

It is manifested here that the incremental filler contents which is mostly clay minerals may influence the thermal stability in PA6 with 10.0 wt. \% OBMFs nanocomposite. In addition to this, the heat capacity results presented in Table 4 showed significant number in heat capacity reduction (about $47 \%$ decrease) which also indicated the increase in thermal conductivity of the material and also indicated the potential incremental heat release property of 
the material under combustion condition. These findings are also agreed with the morphological observations in Fig. 3 (e) which showed 10.0 wt. \% of OBMFs incurred the agglomeration in PA6 with 10.0 wt. \% OBMFs nanocomposite.

It is interesting to mention here that the time needed for PA6 with $7.5 \mathrm{wt} . \%$ OBMFs to reach D1/2 is less than the time needed for PA6 with $2.5 \mathrm{wt}$ \% OBMFs (unsaturated exfoliation). On the other hand PA6 with 7.5 wt. \% nanocomposite took more time to reach $D 1 / 2$ than the time is taken by neat PA6. Additionally the temperature at D1/2 for PA6 with 7.5 wt. \% OBMFs is the lowest among the PA6/OBMFs nanocomposites indicating the best heat capacity material among these PA6/OBMFs nanocomposite material. The ordered intercalated structure within the PA6 with 7.5 wt. \% OBMF may have influenced its heat capacity in this manner which is also noticeable in the morphological observations in Fig. 3 (d). There is an incremental trend of residue left at $600{ }^{\circ} \mathrm{C}$ except PA6 with 10.0 wt. \% OBMFs nanocomposite presented in Table 2. It can be explained by the findings in this analysis for PA6 with 10.0 wt. \% OBMFs nanocomposite which showed the incremental thermal conductivity may generate excessive heat in the interlayer between clay platelets which may affect the decomposition of fractions of total filler contents.

\subsection{Differential Scanning Calorimetry (DSC)}

In order to obtain information about the polymorphic behaviour in PA6/OBMFs and to evaluate the influence of fillers on thermal degradation 
behaviour of nanocomposite materials, nonisothermal measurements were conducted using a Differential Scanning Calorimeter (DSC) and the results are shown in Fig. 6.

[Fig. 6:]

Comparing different thermograms in Fig. 6(b) no major changes in melting temperature is observed and there are two peaks present in thermograms at melting temperature of PA6 and PA6/OBMFs nanocomposites. there is a peak at $212.5^{\circ} \mathrm{C}$ which is representative of the gamma crystal phase whilst a stronger melting peak at $\sim 220^{\circ} \mathrm{C}$ typically associated with the alpha phase is observed in the neat PA6 and PA6/OBMF nanocomposites.

Heat capacity is believed to be one of the main factors influencing the thermal degradation nature and behaviour of polymer nanocomposites [21]. This heat capacity has become an important part of nanocomposite material characterisation. Based on the three distinct peaks obtained in thermograms in Fig. 6, the important features explored for PA6 and its nanocomposites ( $\mathrm{Tg}$, Tm and Tc) are discussed in this section.

The heat capacity peak at melting temperature phase was used to identify the $\%$ of crystallinity of the material. The $\%$ of crystallinity of PA6 and its nanocomposites is calculated using the following equation:

$\% \quad$ crystallinity $=\quad[\Delta H m \quad-\quad \Delta H c] / \Delta H m^{0} \quad{ }^{*} 100 \%$

Where $\Delta H m$ is the heat of melting, $\Delta H c$ the heat-of cold crystallisation which is not present in this experiment $\left(\Delta H c=0\right.$ in this case), and $\Delta H m^{\circ}$ is a reference 
value if the polymer were $100 \%$ crystalline. All the units are in $\mathrm{J} / \mathrm{g}$ and the value of $\Delta H m^{\circ}$ is $230.1 \mathrm{~J} / \mathrm{g}$ [24].

[Table 3:]

It is clearly evident from the investigation that there is not any significant effect of OBMFs on the melting temperature and \% of crystallinity in PA6/OBMFs nanocomposite. It can be inferred here that there is an increasing trend of $\%$ of crystallinity in PA6 nanocomposites with the increase of filler content in the materials except in $10.0 \mathrm{wt}$. \% which showed a drop in \% of crystallinity presented in Table 3.

The heat capacity of PA6 and its nanocomposites have been identified using the integrated two points at crystallisation peak baseline presented in Fig. 6 (c). The heat capacity of material can be represented by the following equation:

$C_{p}$

$(\delta Q / \delta T)$

(2)

Where $C_{p}$ is the heat capacity and expressed in $\mathrm{JK}^{-1}, Q$ is the heat energy in Joule and $\mathrm{T}$ is the temperature expressed as ${ }^{\circ} \mathrm{C}$ or $\mathrm{K}$. To determine the heat capacity from a heat flow $(\mathrm{W} / \mathrm{g})$ thermogram against temperature, the Eq. (2) may be represented as the following:

$C_{p}$

$=$

$(\delta Q / \delta t)$

$\mathrm{X}$

$(\delta t / \delta T)$ 
In Eq. (3) $\delta Q / \delta t$ is the heat flow and $\delta t / \delta T$ is the reciprocal heating rate [25]. By using Eq. (3), the specific heat capacity of PA6 and PA6/OBMFs nanocomposite samples are presented in Table 4.

\section{[Table 4:]}

The heat capacity of PA6/OBMFs nanocomposites also shows the similar trend as $\%$ of crystallinity. It can be articulated by investigating the results in Table 4 that these nanocomposite materials may absorb the optimum heat energy when the polymer intercalated with the OBMFs platelets. Based on the findings of this study, it may be inferred that if the OBMF content exceeds 7.5 wt. \% in the PA6 content limit in PA6/OBMFs nanocomposites, the material may deteriorate the heat capacity property significantly as noticeable in the results in Table 4. By increasing filler content from $7.5 \mathrm{wt}$. \% to $10.0 \mathrm{wt}$. \%, the heat capacity of the material decreases about $47 \%$. Investigating these results, 7.5 wt. \% OBMF may be the optimal content to ensure maximum heat capacity.

Investigating the aforementioned two important properties (\% of crystallinity and heat capacity) of polyamide semi crystalline polymer nanocomposite, it is also interesting to see how the polyamide chain reacts with the crystalline nanofiller. It is believed that there are two interphases present in polyamide/layered silicate nanocomposites. One is between the crystal fraction and amorphous fraction in polyamide chain and the other one is between inorganic filler and polymer matrix [14]. The heat capacity, $C p$ at the 
glass transition phase is identified and using this heat capacity, the RAF is calculated using the following equations.

$R A F \quad=\quad 100 \quad-\quad$ crystallinity $\quad-\quad \Delta C_{p} / \Delta C_{p} \quad$ pure

Where $\Delta C_{p}$ and $\Delta C_{p}$ pure are the heat capacity increments at the glass transition temperature of semi crystalline polymers such as PA6 and PA6/OBMFs nanocomposites in this analysis and the pure amorphous polymer respectively. Schick (2017) also mentioned in DSC application note that the RAF can also be calculated from heat capacity according to eq. 4 replacing the crystallinity by the nanoparticle fraction.

$R A F=100-$ filler content $-\Delta C_{p} / \Delta C_{p}$ pure

[Table 5:]

Based on the eq. 5, the crystal fraction of neat PA6 in this analysis is avoided and hence the CF' value in Table 5 for neat PA6 is 0 , to describe the net incremental fraction of crystallinity in nanocomposite due to adding the inorganic filler (assumed 100\% crystal phase in filler structure) and also to identify the net changes in interface between amorphous fraction of polyamide chain and nanofiller crystals. It can be concluded that the rigid amorphous fraction which is noncrystalline but does not participate in the glass transition due to the parts of the molecules which are fixed because of immobilisation of molecules in polymer chain [14] [16].

Investigating the measured curves at $\mathrm{Tg}$ as illustrated in Fig. 6(a) there is not any significant changes in glass transition temperature for neat PA6 and 
PA6/OBMFs nanocomposites. To determine the RAF and MAF value of PA6 and its nanocomposite, the heat capacity peak at $\mathrm{Tg}$ was considered. The reference value for $\Delta C_{p \text { pure }}$ for PA6 and its nanocomposites was $0.15 \mathrm{~J} /(\mathrm{gK})$ in this study [14]. Considering both eq. 4 and eq. 5 there is a good agreement found in this analysis termed as Total Immobilised Fraction (TIF) which is the sum of either RAF and CF or RAF' and CF', highlighted in Table 5 and in Fig. S4 (supplementary information).

[Fig. 7:] [Fig. 8:]

From the results finding in Table 5 and the Fig. 7 one can infer that when the ratio between TIF and MAF is 1 (50\% TIF line in Fig. 7) in PA6/OBMFs nanocomposites there are three significant points found in its sigmoidal curve. These three points represent exfoliation (first point), intercalation (second point) and agglomeration (third point). It is also articulated here that from the Fig. 7 one can conclude that upto 4.2 wt\% OBMFs content generate exfoliation, 4.2 to $6.8 w t \%$ OBMFs content influence exfoliation induced intercalation, 6.8 to $9.0 \mathrm{wt} \%$ OBMFs incur intercalation induced agglomeration and above 9.0 wt\% OBMFs cause agglomeration in the nanocomposite structure. This MAF, RAF and OBMFs platelets and their schematic structures are shown in Fig. 8.

\subsection{X-ray Diffraction (XRD) analysis}


Fig. 9(a) displays the wide-angle XRD patterns of OBMFs nanoclays and PA6/OBMFs nanocomposites associated with different weight percentage of OBMFs in stacked form whereas in Fig. 9 (b) displays the overlaid XRD patterns of nanocomposite materials in common scale. Low-angle peaks in WAXD assists in quantifying the changes in layer spacing. Considering lowangle in WAXD pattern in Fig. 9(a) the graph clearly shows that the original peak of OBMFs (marked by red circle in Fig.9) is completely absent in the diffraction patterns of PA6 with $2.5 \mathrm{wt} \%, 5.0 \mathrm{wt} \%$ and $10.0 \mathrm{wt} \%$ OBMFs nanocomposites (marked by green circle in Fig.9) demonstrating that the clay is dispersed on a nanometric scale in these systems [26]. XRD patterns of polymeric layered silicates are well established in the literature. Comparing qualitatively the XRD patterns of the materials in this study and literature findings, it can be concluded that OBMFs is exfoliated in PA6 with $2.5 \mathrm{wt} \%$, $5.0 \mathrm{wt} \%$ and $10.0 \mathrm{wt} \%$ nanocomposites and it is intercalated in PA6 with 7.5 wt\% OBMFs nanocomposite (marked by blue circle in Fig. 9) [27-29]. However, by monitoring the position, shape, and intensity of the basal reflections from phase initiation in PA6 with 10.0 wt\% OBMFs (marked by golden circle in Fig. 9) it can be assumed that the incremental loading of fillers (here more than 7.5 wt\% OBMFs) generates agglomeration in PA6/OBMFs nanocomposites.

[Fig. 9] 
Fig. 9 (c) shows the peaks of OBMFs nanoclays compared with those of the different minerals present in the montmorillonite sample (reference material).

In this study full dispersion is not achieved which is attributed due to the insufficient shear stress and the short residence time in extrusion process. This poor dispersion is noticeable in SEM images in Fig. 3. From the findings from literature it is articulated that PA6 exhibited two dominant monoclinic crystalline forms $\alpha$ and $y$ [30]. Although it is highlighted in the literature that the XRD peaks of $\alpha$ form at room temperature are located around $2 \theta=21$ and $24^{\circ}$, and also indexed as (200) and (002) / (202) diffractions, in this study a strong peak attributed of $\alpha$ form is found at $21^{\circ}$ [30][31]. However at $23^{\circ}$ a weak peak is noticeable in composite materials. There are a few small but sharp peaks are noticeable in PA6 with 5.0 wt\% OBMFs, PA6 with 7.5 wt\% OBMFs and PA6 with 10.0 wt\% OBMFs nanocomposites which is evident of the influence of barite phases present in OBMFs and the presence of this barite phases in PA6 with 5.0 wt\% OBMFs nanocomposite is presented in Fig. $2 \mathrm{~b}$ as an example. The strong peaks of barite is clearly noticeable at $2 \theta=$ $27.2^{\circ}, 29.1^{\circ}, 35.9^{\circ}, 42.7^{\circ}, 47.3^{\circ}$ and $54.1^{\circ}$ locations which is believed to influence PA6 with 10.0 wt\% OBMFs nanocomposite behaving as a thermal conductive material.

[Fig. 10]

Fig. 10 a shows the different mineral phases present in nanocomposite materials, in particular the different clay minerals present in nanocomposites. By using Rietveld refinement software, the peaks corresponding to the sets in 
JCPDS cards 12-219 and 29-1499 were identified as montmorillonite, as presented in Fig. 10 a . Since OBMFs is a complex mixture of different minerals and compounds, it is difficult to present a complete compositional database profile, but from this study it is highlighted that muscovite, barite and montmorillonite are the main dominant clay mineral phases present in PA6/OBMFs nanocomposites.

The $d_{001}$ spacing was calculated from peak positions using Bragg's law $n \lambda=$ $2 d \sin \theta$ where $\lambda$ is the wavelength of $\mathrm{X}$-ray radiation used in the experiment, $d$ represents the distance between diffraction lattice planes and $\theta$ is the half diffraction angle. In the case of OBMFs (Fig. 11 a), a diffraction peak at $2 \theta=$ $7.500^{\circ}$ was observed which corresponds to a $d$-spacing of $9.1 \AA$. This is very close to the XRD pattern of neat PA6 (Fig. 11 a) at $2 \theta=8.000^{\circ}$ with a $d-$ spacing of $11.042 \AA$. The $d$-spacing of PA6 with $2.5 \mathrm{wt} \%$ and $5.0 \mathrm{wt} \%$ OBMFs nanocomposites were identified $14,477 \AA$ and $15.768 \AA$ corresponding the reflection peaks at $2 \theta=6.100^{\circ}$ and $2 \theta=5.600^{\circ}$ respectively. The $d$-spacing of PA6 with 7.5 wt $\%$ and 10.0 wt\% OBMFs nanocomposites were determined at $2 \theta=6.700^{\circ}$ and $2 \theta=6.400^{\circ}$, respectively, which represent the values of $13.182 \AA$ and $13.799 \AA$. The trend of $d$-spacing increment is not consistent. The incremental trend of $d$-spacing in PA6/OBMFs is noticeable with PA6 with $2.5 \mathrm{wt} \%$ and $5.0 \mathrm{wt} \%$. Surprisingly $d$-spacing reduces in PA6 with $7.5 \mathrm{wt} \%$ OBMFs and then a little increase of $d$-spacing is observed in PA6 with 10.0 wt\% nanocomposites. It can be inferred here that exfoliation of clay minerals may increase the basal spacing in PA6 with 2.5 and 5.0 wt\% OBMFs nanocomposites, whereas intercalation of clay platelets may influence the 
basal spacing in PA6 with $7.5 \mathrm{wt} \%$ OBMFs nanocomposite. The basal spacing in PA6 with 10.0 wt\% OBMFs is not understood clearly. On investigating the SEM images in Fig. 3, it might be anticipated that PA6 with $10.0 \mathrm{wt} \%$ OBMFs nanocomposites may possess agglomeration of platelets and also some platelets may have exfoliated locally.

Furthermore, Kim et al., [32] described two parameters which can dictate the degree of exfoliation - Bragg's $d_{(001)}$ and apparent crystallite size of silicate $\left(D_{\mathrm{c}}\right)$. In addition of the interlayer spacing which is presented in previous paragraph, full width at half maximum (FWHM) of the (001) reflections is also useful to identify the degree of filler dispersion in this study. The FWHM of OBMFs, PA6 with 2.5 wt\% OBMFs, PA6 with 5.0 wt $\%$ OBMFs, PA6 with 7.5 wt\% OBMFs and PA6 with 10.0 wt\% OBMFs are 0.600, 0.700, $0.400,1.000$ and 0.600 respectively. The broader the width of the diffraction peak, the smaller the thickness of silicate layers and the relation of the thickness of silicate layers with the degree of exfoliation is highlighted in the literature [32][33]. It can be assumed considering the FWHM data that OBMFs exfoliated in PA6 with 5.0 wt\% OBMFs and this layered silicates intercalated in PA6 with 7.5 wt\% OBMFs. It was expected that the FWHM of PA6 with 2.5 wt\% would be the lowest number, but this inconsistent result is not clearly understood.

[Fig. 11]

X-ray diffraction patterns of the nanocomposites prepared with different weight percentage of OBMFs contents such as $2.5 \mathrm{wt} \%, 5.0 \mathrm{wt} \%, 7.5 \mathrm{wt} \%$ 
and 10.0 wt\% are illustrated in Fig. 11 b (original data with smoothed line) and Fig. 11 c (smoothed line only). Observing Fig. 11 a c, the basal space in PA6 with 2.5 wt\% and 5.0 wt\% OBMFs nanocomposites is wider than the basal space in neat PA6, resulting that the XRD pattern is wider than that of PA6. The presence of very week XRD peak/crest in PA6 with 2.5 wt $\%$ and 5.0 wt\% OBMFs nanocomposites probably suggests the formation of an exfoliated nanostructure. However, PA6 with 7.5 wt\% OBMFs nanocomposite shows a distinct sharp peaks, which may indicate the formation of an intercalated nanostructure. The XRD pattern in PA6 with 10.0 wt\% OBMFs shows both intercalation and exfoliation characteristics. The XRD patterns in PA6 with 10.0 wt\% OBMFs nanocomposite show exfoliated characteristic up to $2 \theta=$ $5.4^{\circ}$ location, whereas the XRD pattern shows not the same as exfoliated structure or intercalated structure. The intensity of the diffraction in nanocomposites except PA6 with 7.5 wt\% OBMFs nanocomposites also suggests the disordered feature of clay platelets in the nanocomposite. However, the sharp XRD pattern in PA6 with 7.5 wt\% OBMFs nanocomposite indicates the intercalation characteristic of platelets in the PA6 matrix.

\subsection{TEM analysis}

TEM images of OBMFs filled PA6 polymer nanocomposites are shown in Fig. 12. A generally good state of dispersion was observed in PA6 polymer matrix. There were small clusters of OBMFs platelets observed in PA6 matrix in lowest concentration of fillers content such as 2.5 wt $\%$ of OBMFs in PA6 matrix in this study. However, these clusters tended to create agglomeration 
in higher weight percentage of OBMFs in PA6 matrix which is shown in Fig. 12(c) and (d).

[Fig. 12]

The size of the agglomerates was in the range of 100 to $150 \mathrm{~nm}$, whereas the size of the small clusters was in the range of 10 to $30 \mathrm{~nm}$. From the micrographs in Fig. 12 (a) (b), it could be observed that OBMFs was exfoliated randomly. However, there were agglomerates noticeable in Fig. 12 (c) (d), which can be inferred that an incremental addition of OBMFs in PA6 matrix may hinder the platelets to be separated from each other. In addition, the higher content of OBMFs is prone to cause agglomeration in PA6 matrix and a number of local exfoliation is also visible which is observed in Fig. 12 (c) (d).

\section{Conclusion}

In this work, we have investigated the thermal degradation behaviour of PA6 nanocomposite containing oil based drilling fluid waste as nanofiller. PA6/OBMFs nanocomposite exhibit different characteristics under different conditions mainly due to variation in nanomorphology (exfoliation, intercalation and presence of tactoids or agglomeration). From the findings in TGA investigation, OBMFs platelets exfoliated in PA6 matrix in PA6 with 5.0 wt\% OBMFs nanocomposite showed maximum heat resistant property (maximum D1/2 time), OBMFs platelets intercalated in PA6 matrix in PA6 with 
7.5 wt\% OBMFs nanocomposite showed optimum heat absorbance capacity whilst A6 with 10.0 wt\% OBMFs nanocomposite showed maximum thermal stability. Furthermore the heat capacity data at $\mathrm{Tg}$ using DSC provided very useful RAF and MAF information which depicts a sigmoidal curve showing exfoliation point, exfoliation induced intercalation point, intercalation induced agglomeration point and finally the agglomeration point. This new technique to identify the nanomorphology is step forward in the mechanical and thermal characterisation of PA6/OBMFs nanocomposites.

\section{Acknowledgement}

The authors are indebted to Dr Kerr Matthews from School of Pharmacy and Life Sciences, Robert Gordon University, Aberdeen and Dr Laszlo Csetenyi from School of Science and Engineering, University of Dundee for technical assistance and helpful discussions. We would also like to thank Professor John Irvine and Dr David Miller from School of Chemistry, StAndrews University for helping in TEM analysis and we would like to acknowledge the support of the EPSRC Capital for Great Technologies Grant EP/L017008/1.

\section{References}

[1] Fornes T, Paul D. Crystallization behavior of nylon 6 nanocomposites. Polymer. 2003; 44(14):3945-3961. 
[2] Bourbigot S, Devaux E, Flambard X. Flammability of polyamide-6/clay hybrid nanocomposite textiles. 2002ID: 271544.

[3] Njuguna J, Pielichowski K, Desai S. Nanofiller-reinforced polymer nanocomposites. Polymers for Advanced Technologies. 2008; 19(8):947-959.

[4] Morgan AB, Gilman JW. Characterization of polymer-layered silicate (clay) nanocomposites by transmission electron microscopy and X-ray diffraction: A comparative study. Journal of Applied Polymer Science. 2003; 87(8):13291338.

[5] Bourbigot S, Duquesne S. Fire retardant polymers: recent developments and opportunities. Journal of Materials Chemistry. 2007; 17(22):2283-2300.

[6] Leszczyńska A, Njuguna J, Pielichowski K, Banerjee J. Polymer/montmorillonite nanocomposites with improved thermal properties: Part I. Factors influencing thermal stability and mechanisms of thermal stability improvement. Thermochimica Acta. 2007; 453(2):75-96.

[7] Leszczyńska A, Njuguna J, Pielichowski K, Banerjee J. Polymer/montmorillonite nanocomposites with improved thermal properties: Part II. Thermal stability of montmorillonite nanocomposites based on different polymeric matrixes. Thermochimica Acta. 2007; 454(1):1-22.

[8] Seymour RB, Kirshenbaum GS. High performance polymers, their origin and development. : Springer; 1986.

[9] Qin H, Su Q, Zhang S, Zhao B, Yang M. Thermal stability and flammability of polyamide 66/montmorillonite nanocomposites. Polymer. 2003; 44(24):7533-7538. 
[10] Pavlidou S, Papaspyrides C. A review on polymer-layered silicate nanocomposites. Progress in polymer science. 2008; 33(12):1119-1198.

[11] Dennis H, Hunter D, Chang D, Kim S, White J, Cho J, et al. Effect of melt processing conditions on the extent of exfoliation in organoclay-based nanocomposites. Polymer. 2001; 42(23):9513-9522.

[12] Uddin F. Clays, nanoclays, and montmorillonite minerals. Metallurgical and Materials Transactions A. 2008; 39(12):2804-2814.

[13] Carretero MI, Pozo M. Clay and non-clay minerals in the pharmaceutical industry: Part I. Excipients and medical applications. Applied Clay Science. 2009; 46(1):73-80.

[14] Wurm A, Ismail M, Kretzschmar B, Pospiech D, Schick C. Retarded crystallization in polyamide/layered silicates nanocomposites caused by an immobilized interphase. Macromolecules. 2010; 43(3):1480-1487.

[15] Schick C. Study Rigid Amorphous Fraction in Polymer Nano-Composites by StepScan and HyperDSC. 2009;

[16] Schick C, Wurm A, Mohamed A. Vitrification and devitrification of the rigid amorphous fraction of semicrystalline polymers revealed from frequencydependent heat capacity. Colloid \& Polymer Science. 2001; 279(8):800-806.

[17] $\mathrm{Wu} T, \mathrm{Wu}$ J. Structural analysis of polyamide/clay nanocomposites. Journal of Macromolecular Science, Part B. 2002; 41(1):17-31.

[18] Zope IS, Dasari A, Guan F, Yu Z. Influence of metal ions on thermooxidative stability and combustion response of polyamide 6/clay nanocomposites. Polymer. 2016; 92:102-113. 
[19] Pereira C, Martins M. Flame retardancy of fiber-reinforced polymer composites based on nanoclays and carbon nanotubes. Polymer Green Flame Retardants. : Elsevier; 2014. p. 551-595.

[20] Chen G, Shen D, Feng M, Yang M. An Attenuated Total Reflection FT-IR Spectroscopic Study of Polyamide 6/Clay Nanocomposite Fibers. Macromolecular rapid communications. 2004; 25(11):1121-1124.

[21] Pramoda K, Liu T, Liu Z, He C, Sue H. Thermal degradation behavior of polyamide 6/clay nanocomposites. Polymer Degradation and Stability. 2003; 81(1):47-56.

[22] Socrates G. Infrared and Raman characteristic group frequencies: tables and charts. : John Wiley \& Sons; 2001.

[23] Vasanthan N, Salem D. FTIR spectroscopic characterization of structural changes in polyamide- 6 fibers during annealing and drawing. Journal of Polymer Science Part B: Polymer Physics. 2001; 39(5):536-547.

[24] Sichina W. DSC as problem solving tool: measurement of percent crystallinity of thermoplastics. Thermal Analysis Application Note. 2000;

[25] Coleman NJ, Craig DQ. Modulated temperature differential scanning calorimetry: a novel approach to pharmaceutical thermal analysis. International journal of pharmaceutics. 1996; 135(1-2):13-29.

[26] Scarfato P, Incarnato L, Di Maio L, Dittrich B, Schartel B. Influence of a novel organo-silylated clay on the morphology, thermal and burning behavior of low density polyethylene composites. Composites Part B: Engineering. 2016 Aug 1; 98:444-52. 
[27] Vaia RA, Giannelis EP. Lattice model of polymer melt intercalation in organically-modified layered silicates. Macromolecules. 1997 Dec 15; 30(25):7990-9.

[28] Liu TX, Liu ZH, Ma KX, Shen L, Zeng KY, He CB. Morphology, thermal and mechanical behavior of polyamide 6/layered-silicate nanocomposites. Composites science and technology. 2003 Feb 1;63(3-4):331-7.

[29] Ray SS, Okamoto M. Polymer/layered silicate nanocomposites: a review from preparation to processing. Progress in polymer science. 2003 Nov 1; 28(11):1539-641.

[30] Chiu F, Lai S, Chen $\mathrm{Y}$, Lee $\mathrm{T}$. Investigation on the polyamide 6/organoclay nanocomposites with or without a maleated polyolefin elastomer as a toughener. Polymer. 2005; 46(25):11600-11609.

[31] Cho J, Paul D. Nylon 6 nanocomposites by melt compounding. Polymer. 2001; 42(3):1083-1094.

[32] Kim SW, Jo WH, Lee MS, Ko MB, Jho JY. Effects of shear on melt exfoliation of clay in preparation of nylon 6/organoclay nanocomposites. Polymer journal. 2002 Mar; 34(3):103.

[33] Strawhecker KE, Manias E. Structure and properties of poly (vinyl alcohol)/Na+ montmorillonite nanocomposites. Chemistry of materials. 2000 Oct 16; 12(10):2943-9. 


\section{Caption of Figures and Tables}

\section{Figure Captions}

Fig. 1: Comparison of FTIR full scale spectra of PA6 and its nanocomposite.

Fig. 2: Comparison of FTIR spectra between 1200-525 of PA6 and its nanocomposite.

Fig. 3: SEM images of (a) PA6; (b) PA6 with 2.5 wt\% OBMFs; (c) PA6 with 5.0 wt\% OBMFs; (d) PA6 with 7.5 wt\% OBMFs; and (e) PA6 with 10.0 wt\% OBMFs.

Fig. 4: EDX spectra of (a) PA6; (b) PA6+2.5 wt $\%$ OBMFs; (c) PA6+5.0 wt $\%$ OBMFs; (d) PA6+7.5 wt\% OBMFs and (e) PA6+10.0 wt \% OBMFs.

Fig. 5: TGA of PA6 and PA6/OBMFs nanocomposites at: (a) complete thermograms of all samples; (b) $250^{\circ} \mathrm{C}$; (c) D $1 / 2$; (d) $600{ }^{\circ} \mathrm{C}$.

Fig. 6: DSC thermograms of PA6 and its nanocomposites at (a) $\mathrm{Tg}$; (b) $\mathrm{T}_{\mathrm{m}}$ and (c) $T_{c}$.

Fig. 7: Relation between TIF and dispersion behaviour of OBMFs in PA6 matrix.

Fig. 8: Schematic diagram of OBMFs platelets associated with MAF and RIF of PA6 matrix.

Fig. 9: WAXD patterns of (a) OBMFs and PA6/OBMFs nanocomposite in stack form; (b) nanocomposite in common scale; and (c) OBMFs and MMT.

Fig. 10: WAXD patterns of (a) mineral composition of different nanocomposite; (b) new peaks identification in nanocomposites.

Fig. 11: SAXD patterns of (a) OBMFs and PA6/OBMFs nanocomposite in stack form; (b) nanocomposite in common scale; and (c) smoothed nanocomposite profile.

Fig. 12: TEM images of PA6 with 2.5 wt\% OBMFs nanocomposites (a) and (b) and PA6 with 10.0 wt\% OBMFs nanocomposites (c) and (d). 


\section{Table Captions}

Table 1: ATR FT-IR peak assignments (Chen et al., 2004) (Pramoda et al., 2003) (Socrates George, 2004) (Vasanthan and Salem, 2001)

Table 2: \% of crystallinity of PA6 and its nanocomposite using DSC

Table 3: Heat capacity of PA6 and its nanocomposite

Table 4: TGA analysis at different decomposition stages of PA6 and its nanocomposites with different clay loadings

Table 5: TIF determination using DSC 


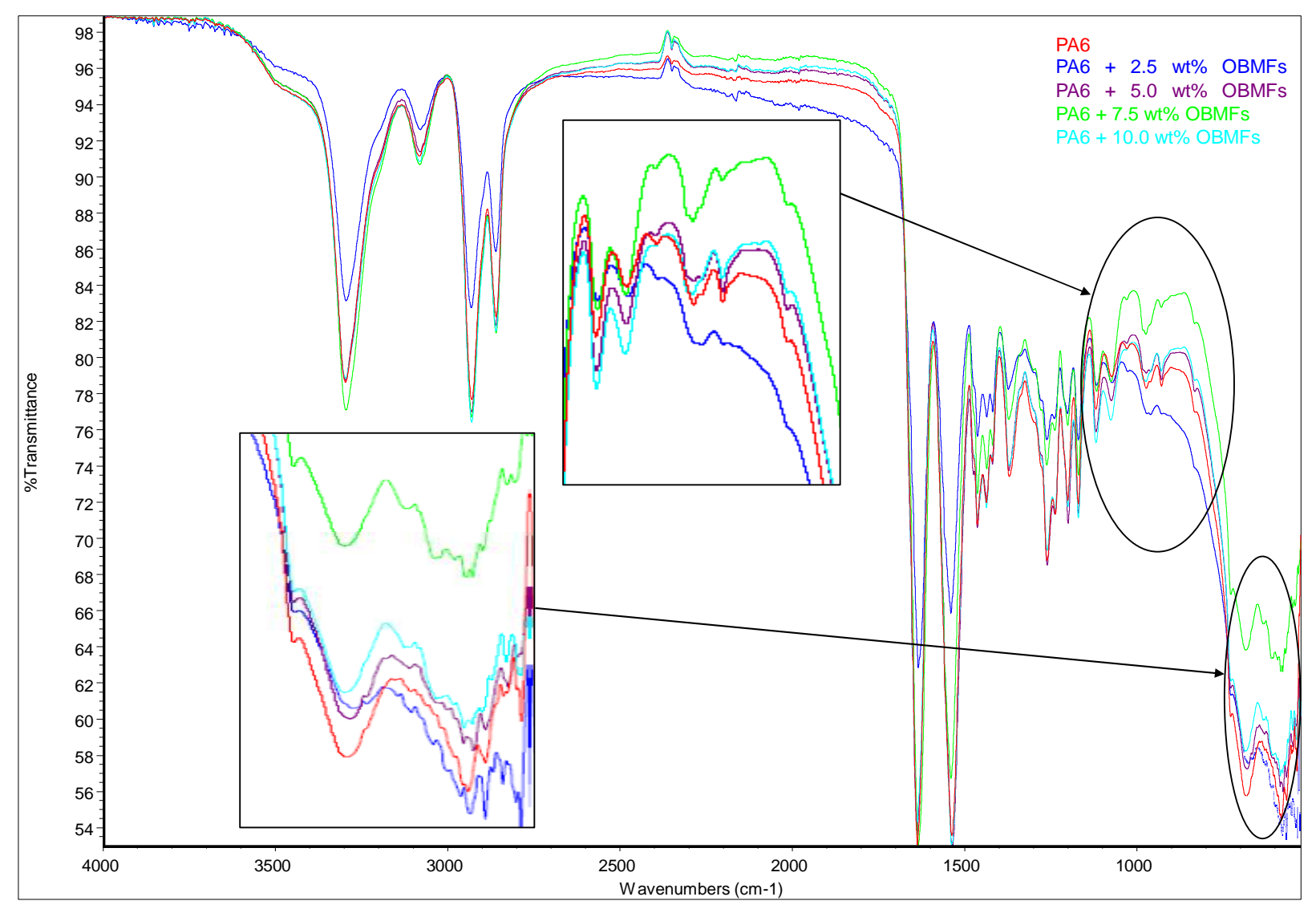

Fig. 1: Comparison of FTIR full scale spectra of PA6 and its nanocomposite. 


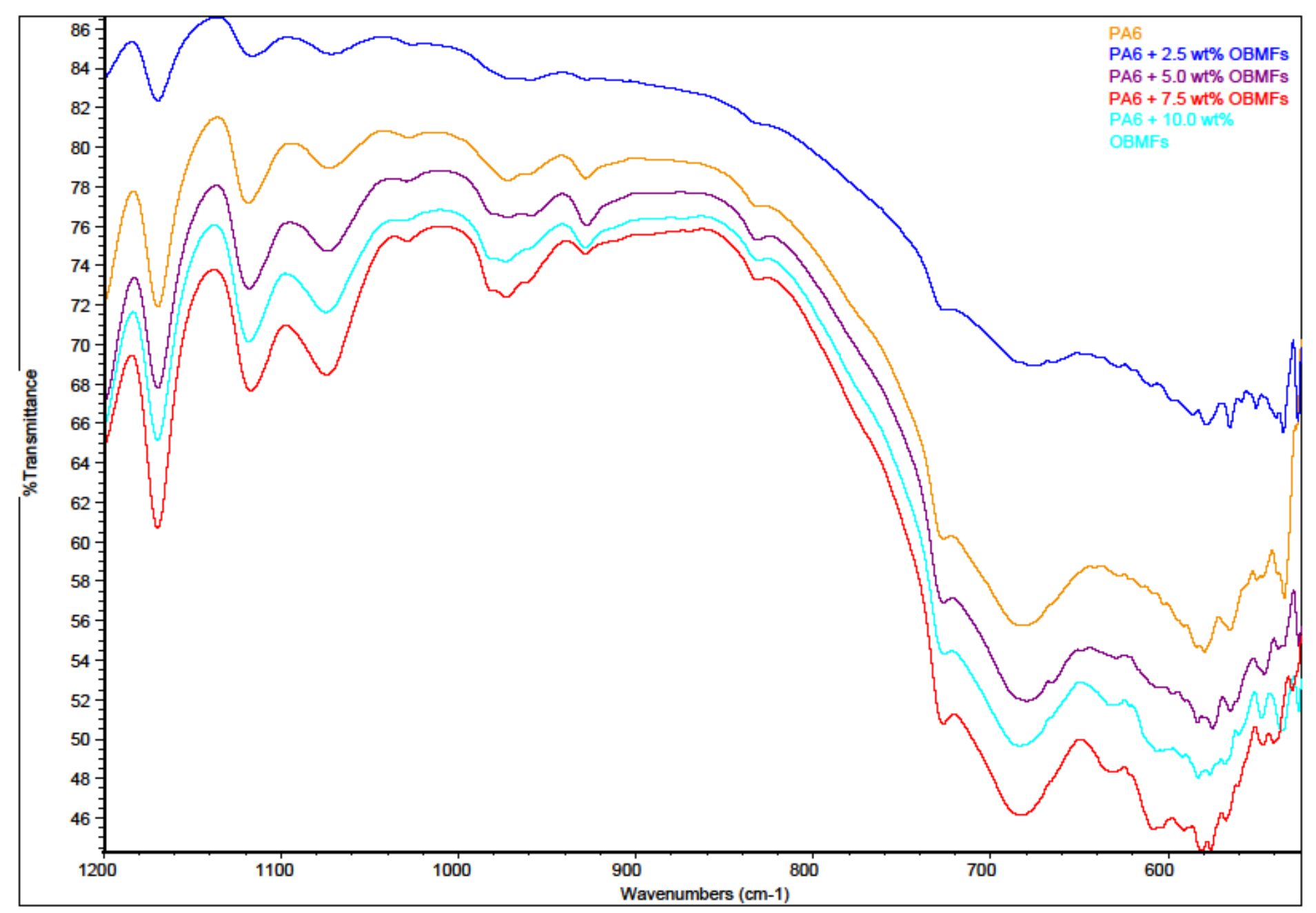

Fig. 2: Comparison of FTIR spectra between $1200-525$ of PA6 and its nanocomposite. 

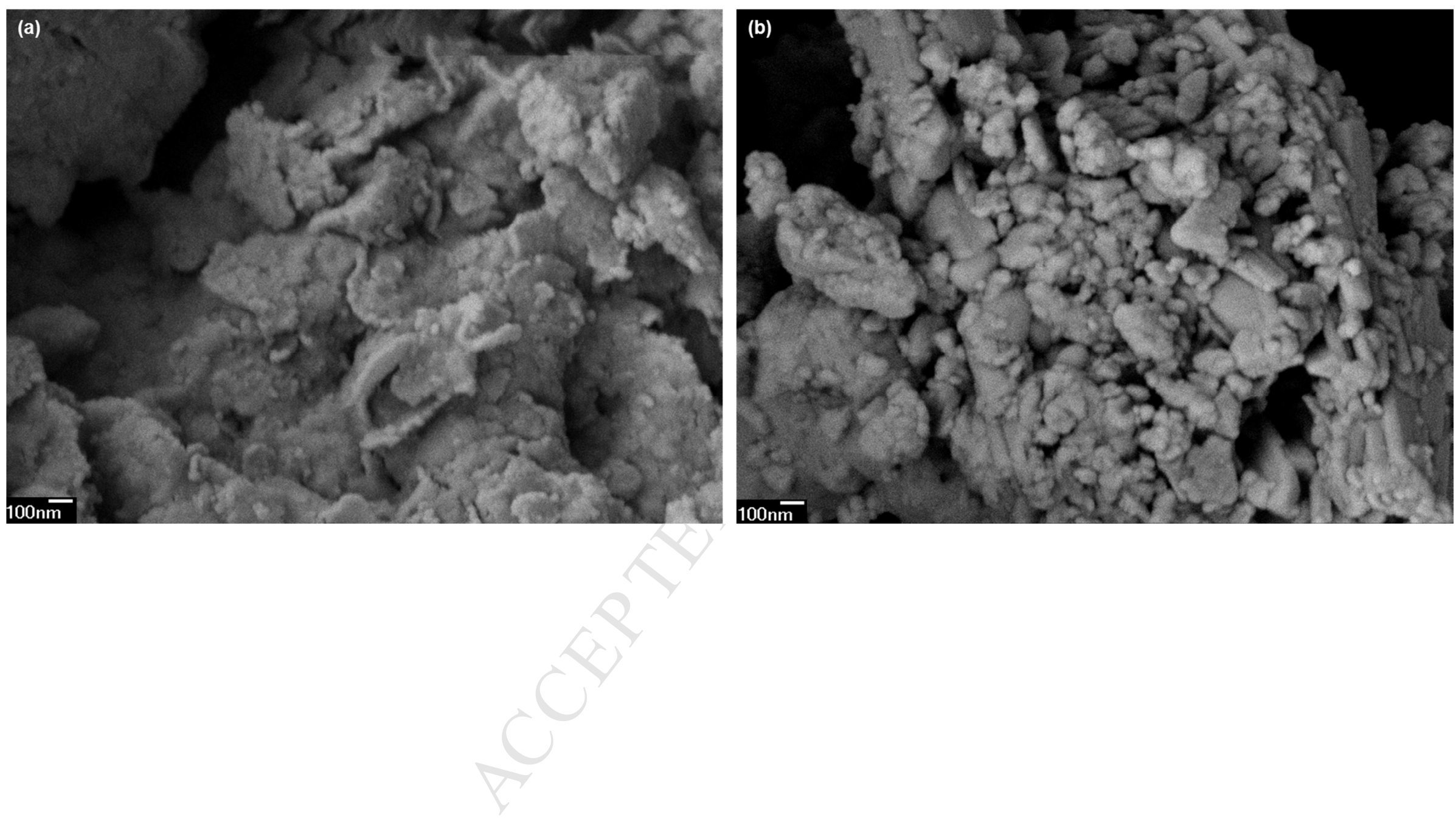


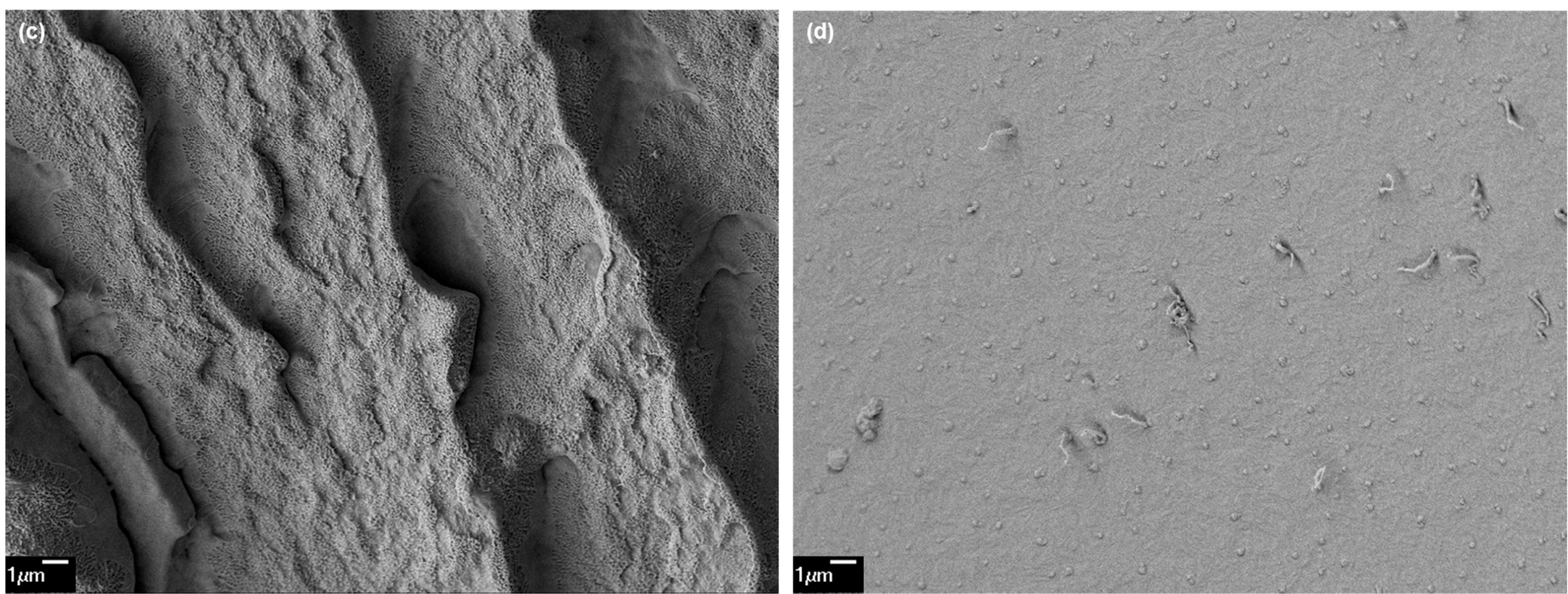



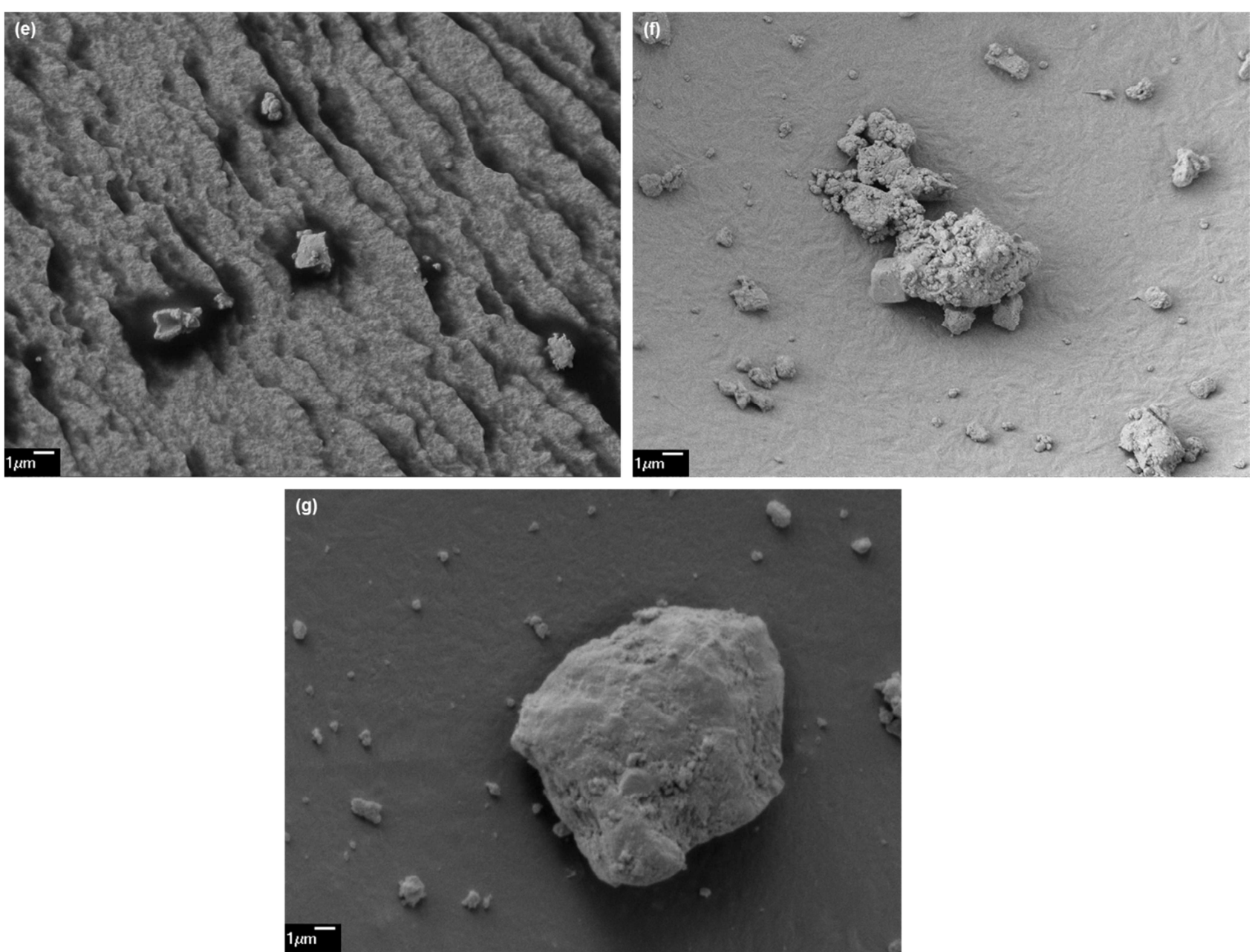

Fig. 3: SEM images of (a) montmorillonite; (b) OBMFs; (c) PA6; (d) PA6 with 2.5 wt\% OBMFs; (e) PA6 with 5.0 wt\% OBMFs; (f) PA6 with 7.5 wt $\%$ OBMFs; and (g) PA6 with 10.0 wt $\%$ OBMFs. 


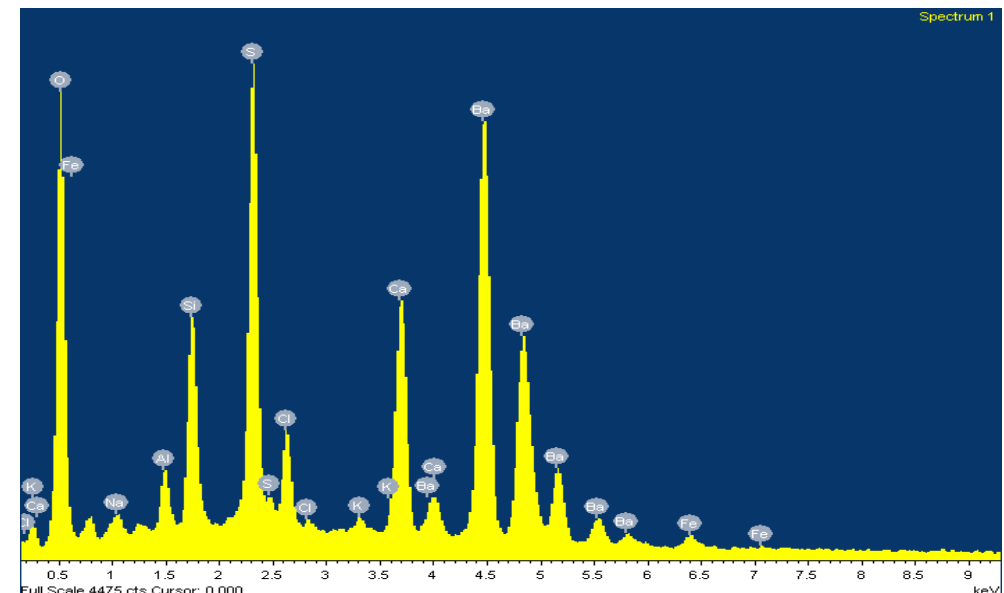

\begin{tabular}{|l|l|}
\hline Element & Atomic\% \\
\hline $\mathrm{O}$ & 61.85 \\
\hline $\mathrm{Na}$ & 0.87 \\
\hline $\mathrm{Al}$ & 1.77 \\
\hline $\mathrm{Si}$ & 5.43 \\
\hline $\mathrm{S}$ & 10.55 \\
\hline $\mathrm{Cl}$ & 2.38 \\
\hline $\mathrm{K}$ & 0.27 \\
\hline $\mathrm{Ca}$ & 5.36 \\
\hline $\mathrm{Fe}$ & 0.52 \\
\hline $\mathrm{Ba}$ & 11 \\
\hline Totals & 100 \\
\hline
\end{tabular}

(a)

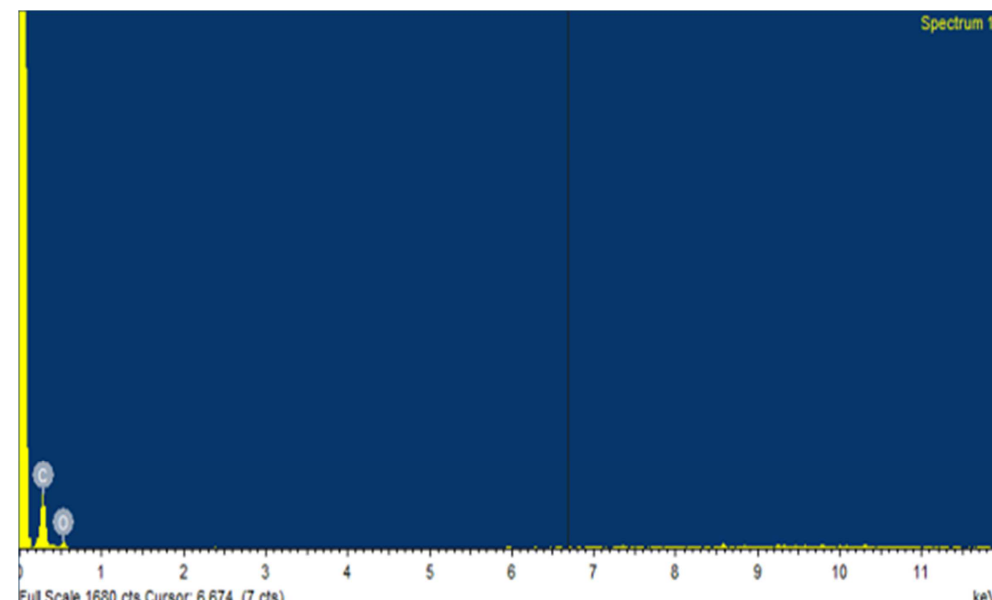

\begin{tabular}{|l|r|}
\hline Element & Atomic\% \\
\hline & \\
\hline $\mathrm{C}$ & 77.42 \\
\hline $\mathrm{O}$ & 22.58 \\
\hline Totals & 100 \\
\hline
\end{tabular}

(b) 


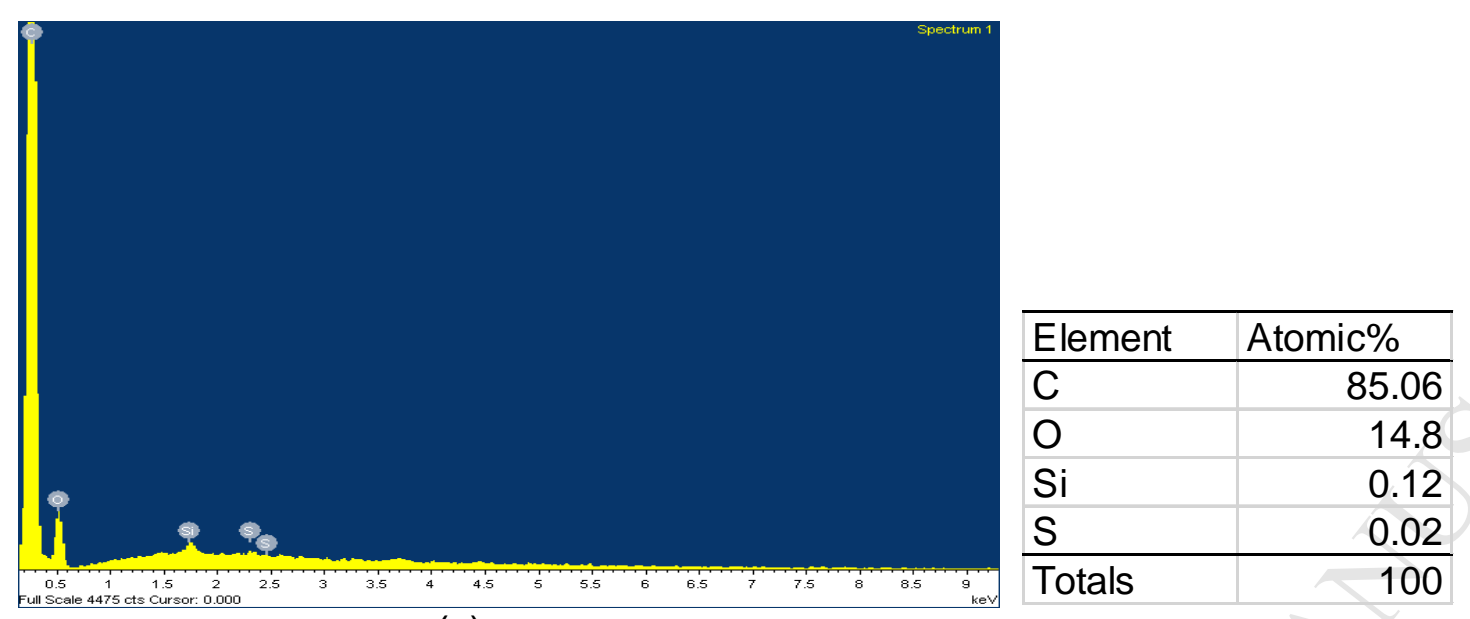

(c)

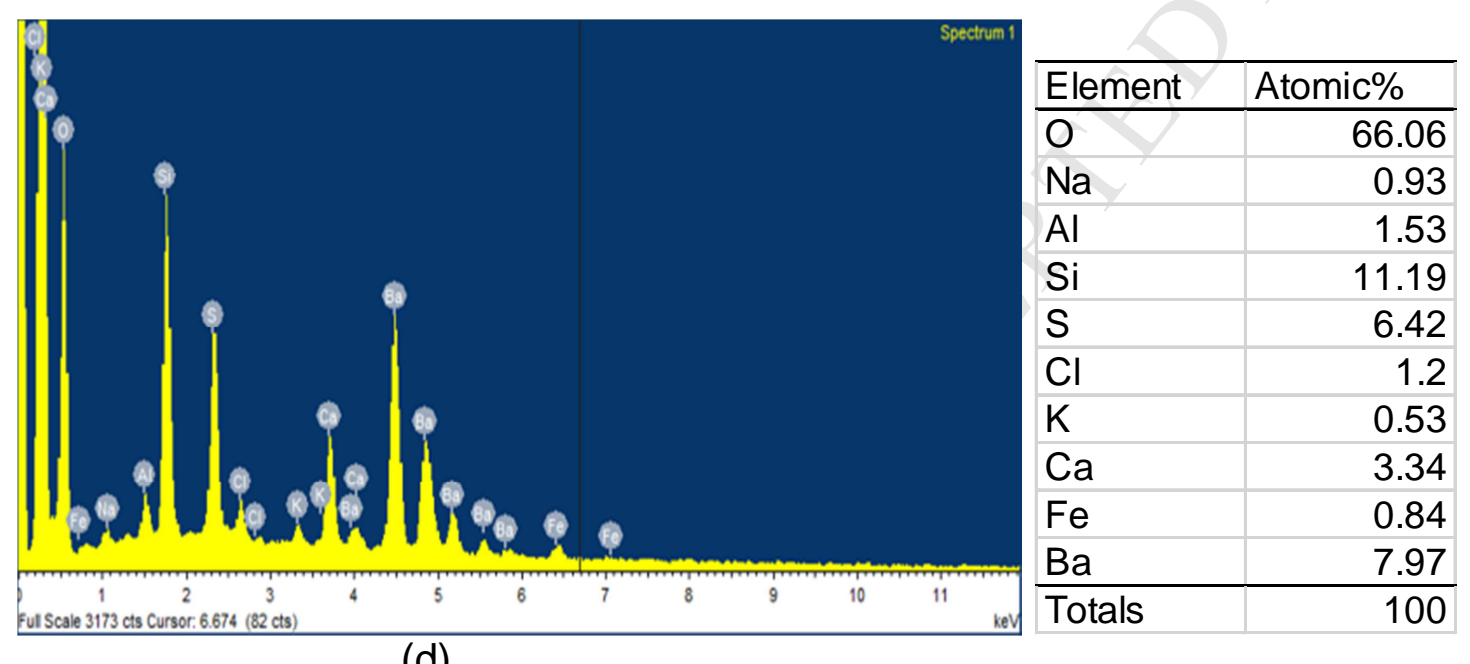

(d) 


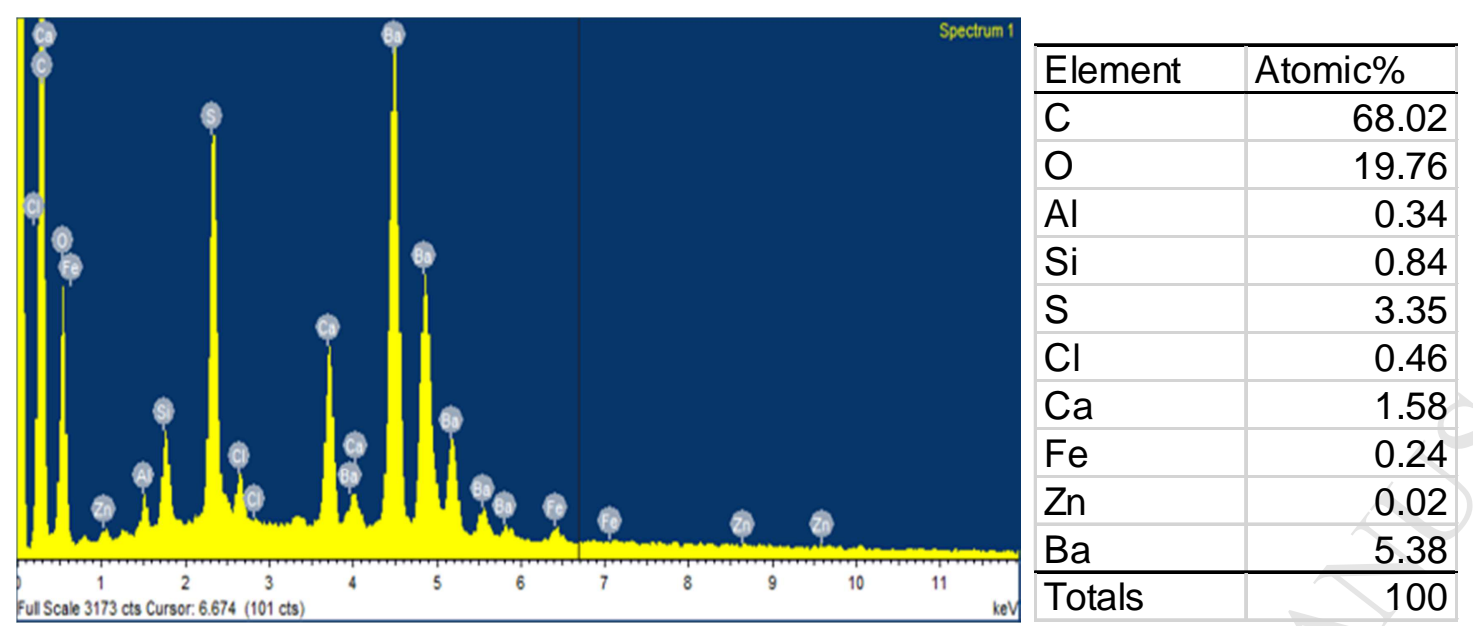

(e)

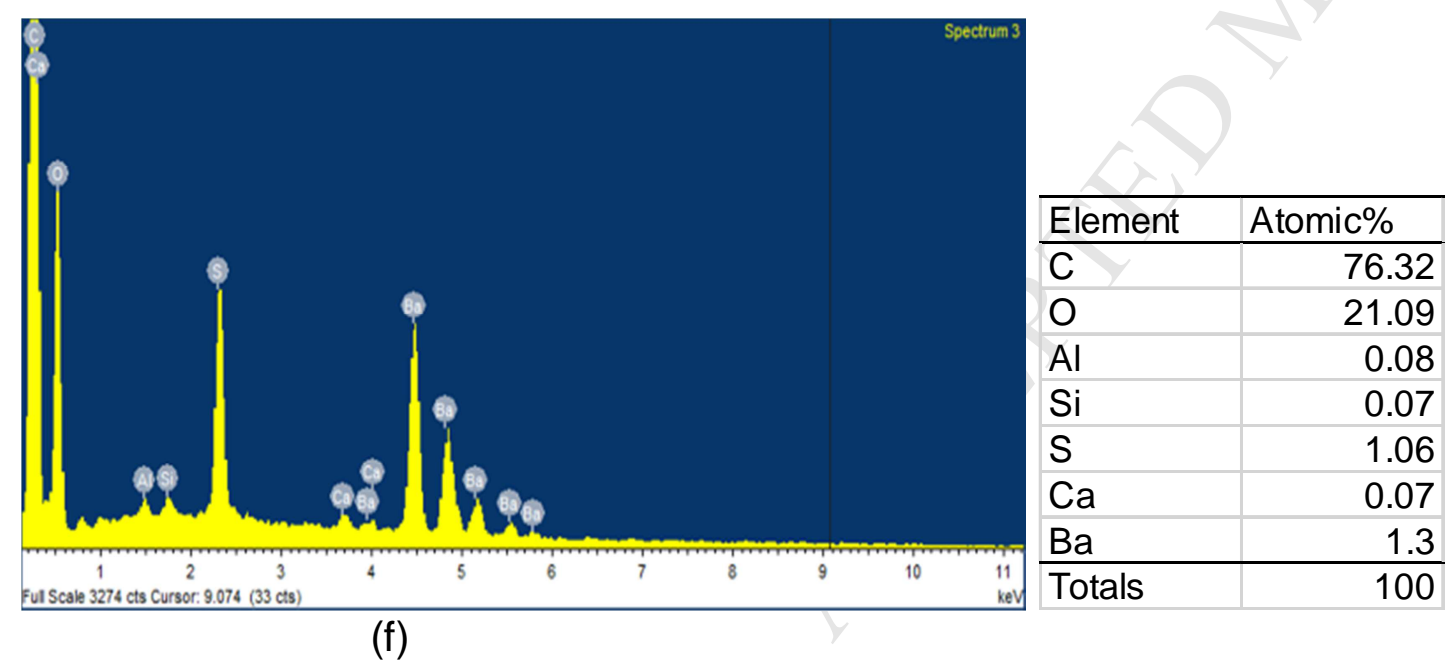

Fig. 4: EDX spectra of (a) OBMFs; (b) PA6; (c) PA6+2.5 wt\% OBMFs; (d) PA6+5.0 wt\% OBMFs; (e) PA6+7.5 wt\% OBMFs and (f) PA6+10.0 wt\% OBMFs. 


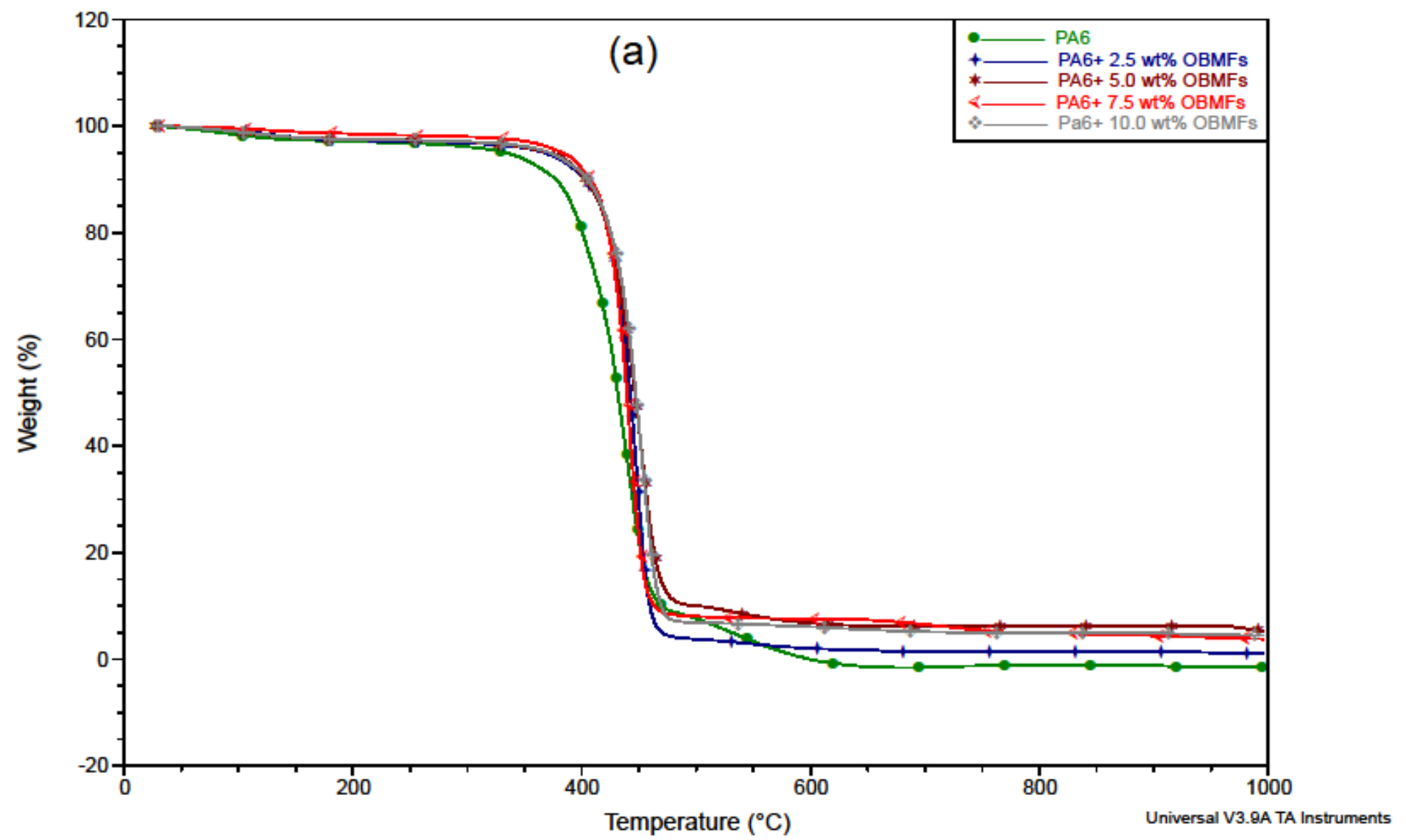




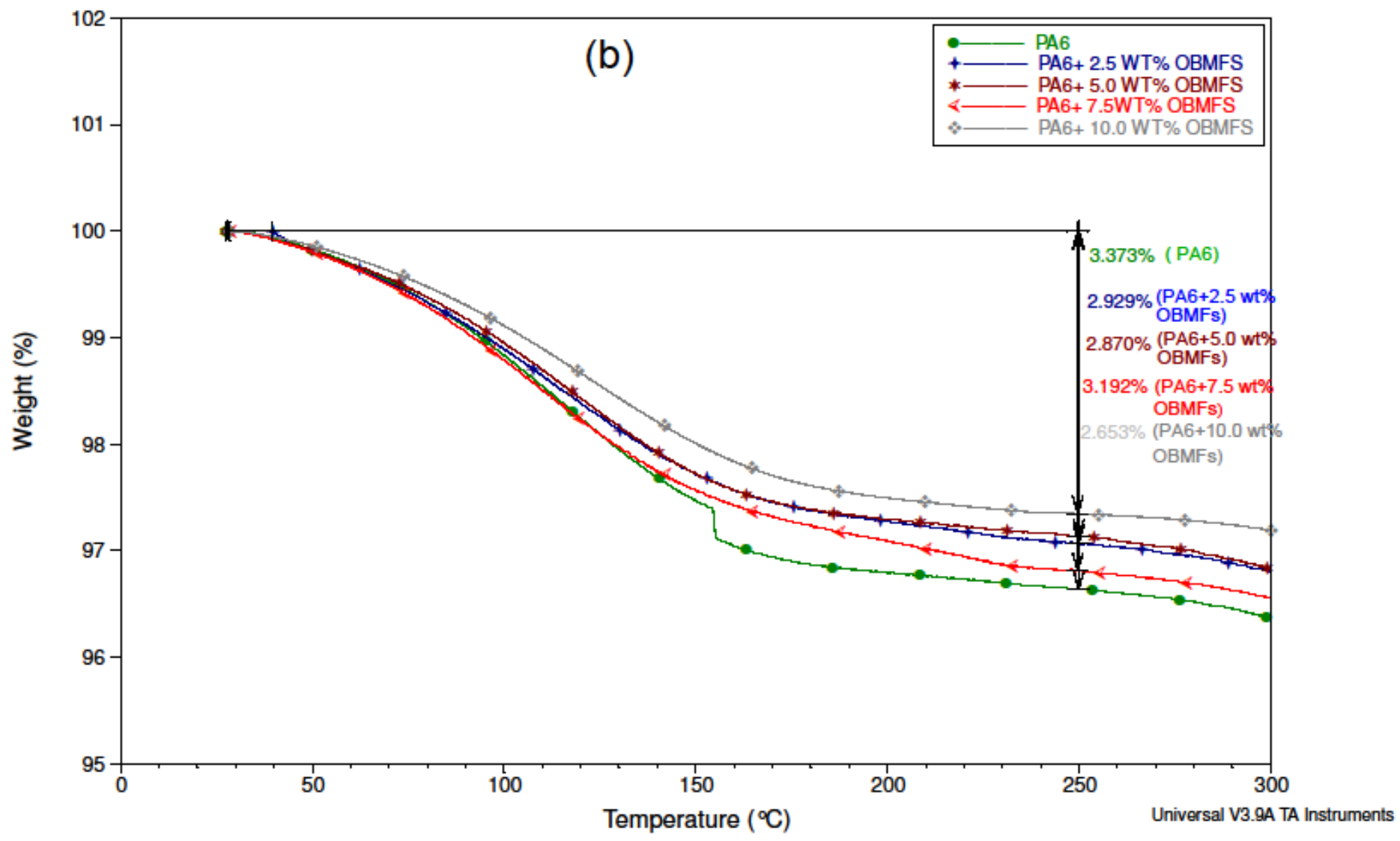




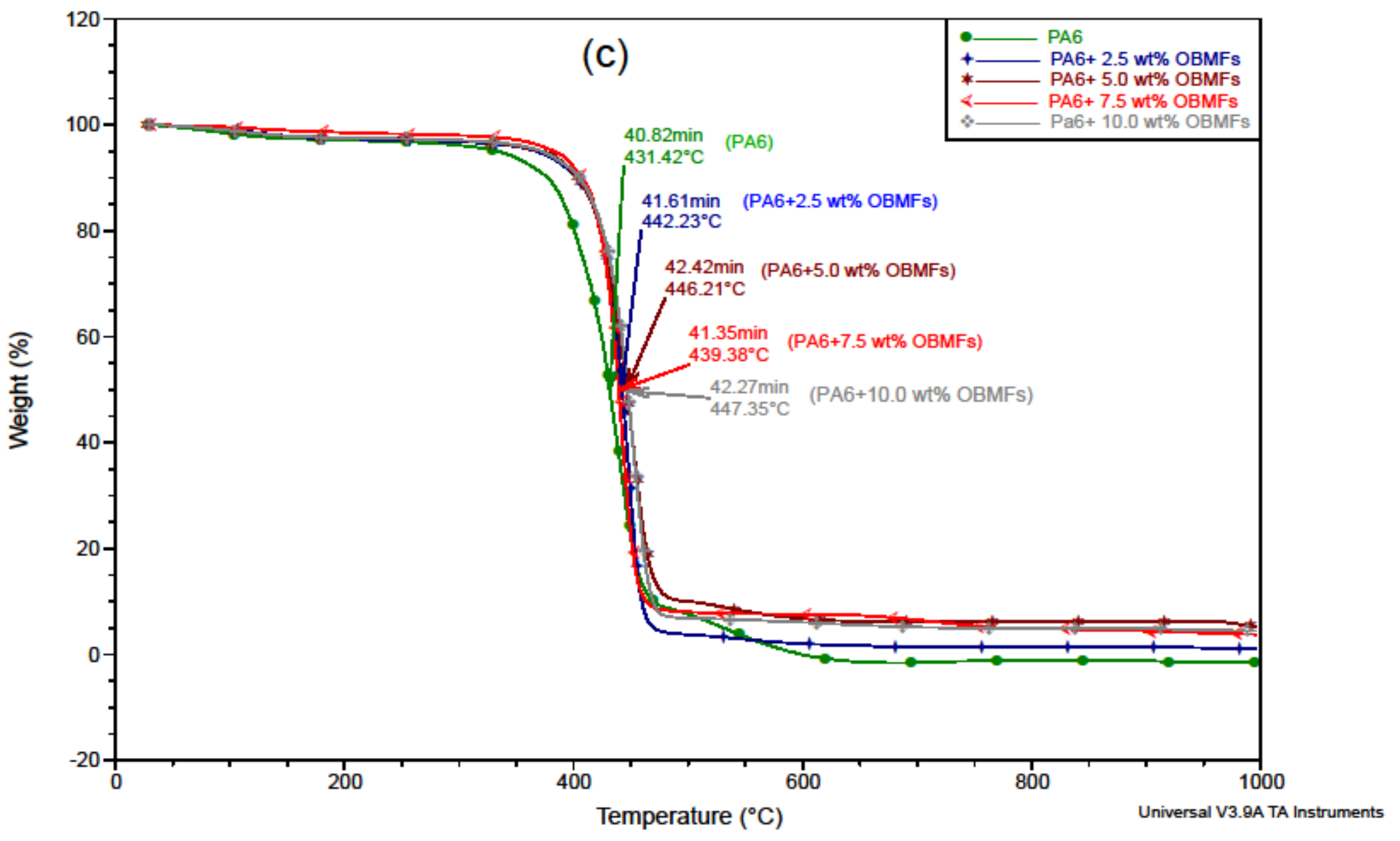




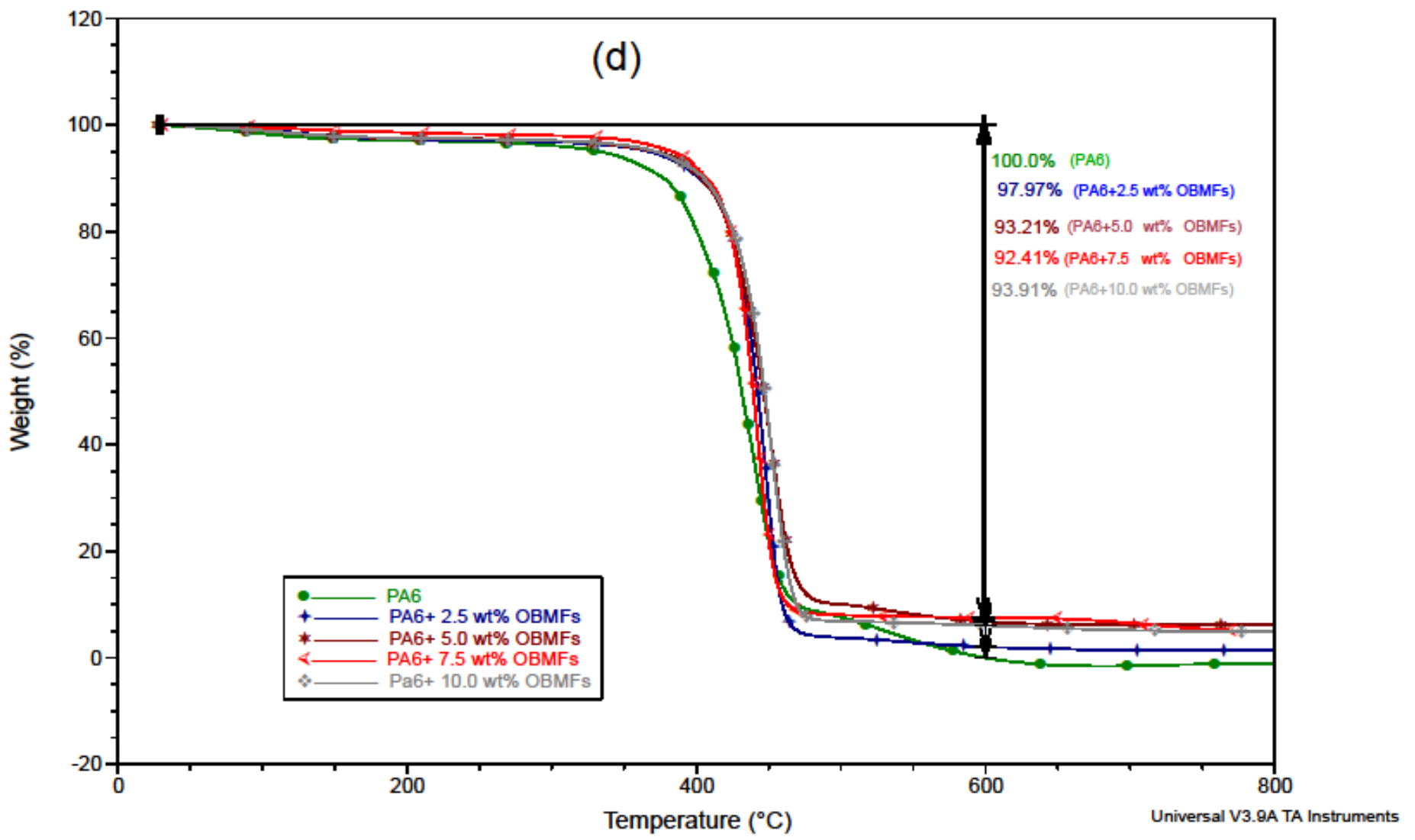

Fig. 5: TGA of PA6 and PA6/OBMFs nanocomposites at: (a) complete thermograms of all samples; (b) $250^{\circ} \mathrm{C}$; (c) $\mathrm{D} 1 / 2$; (d) $600{ }^{\circ} \mathrm{C}$. 


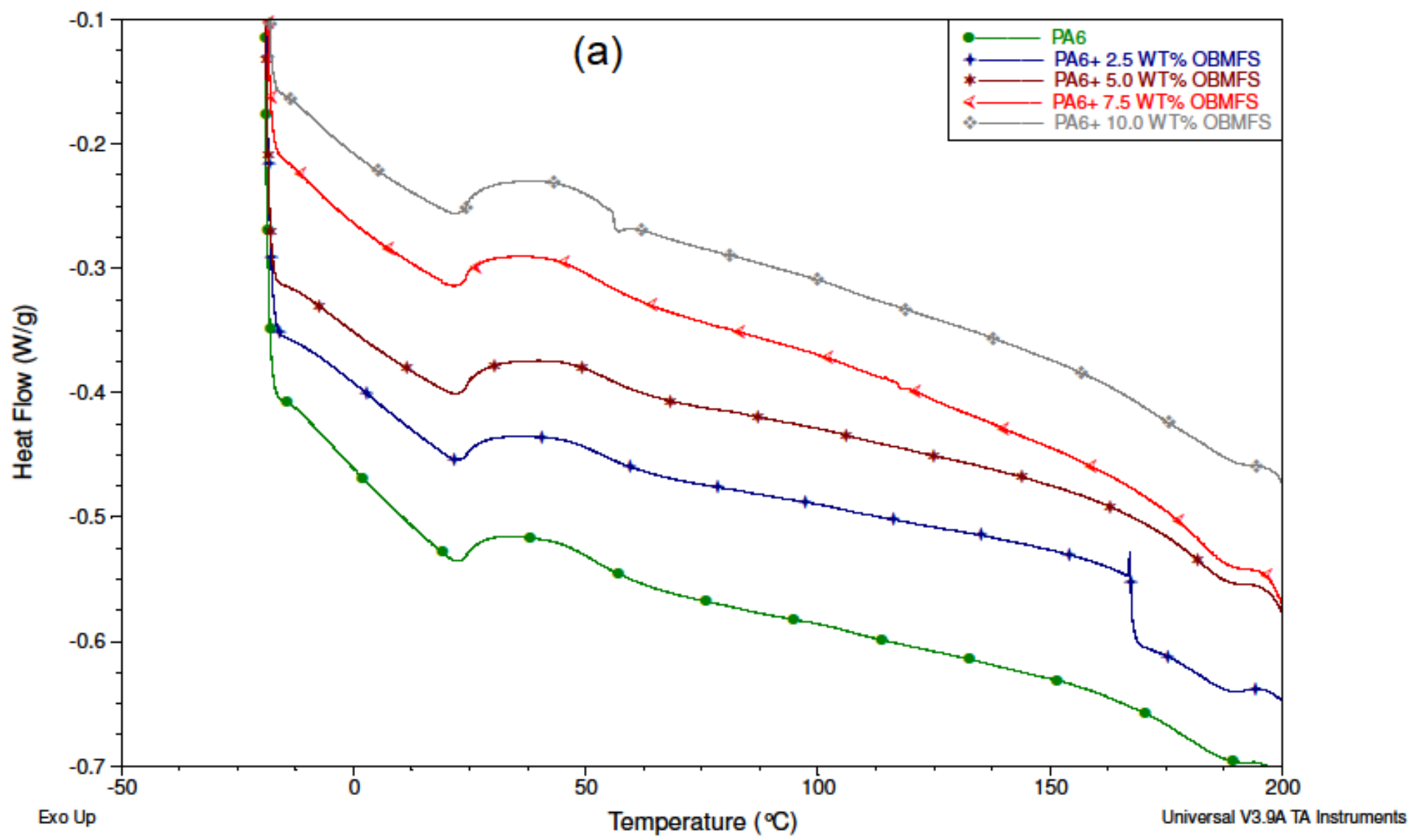




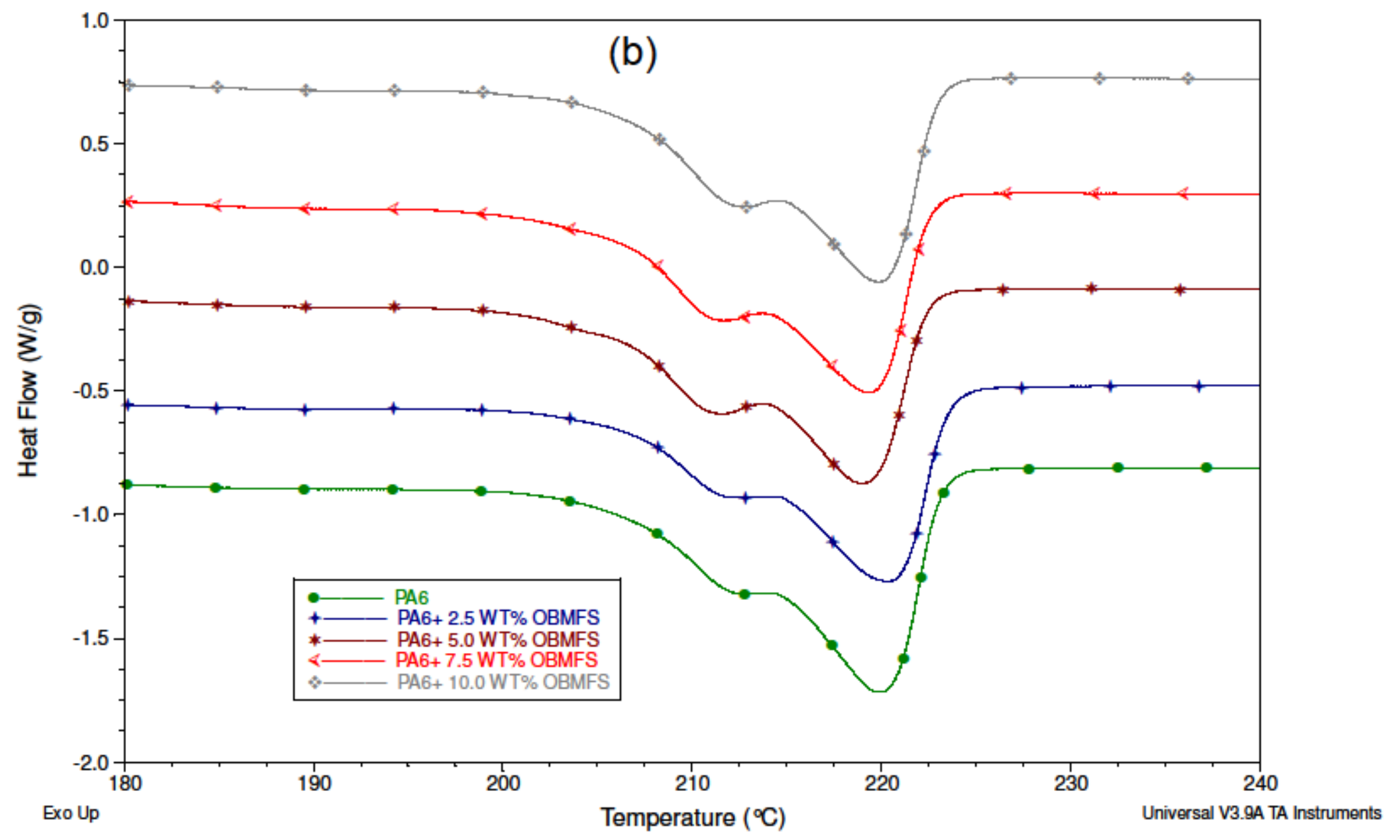




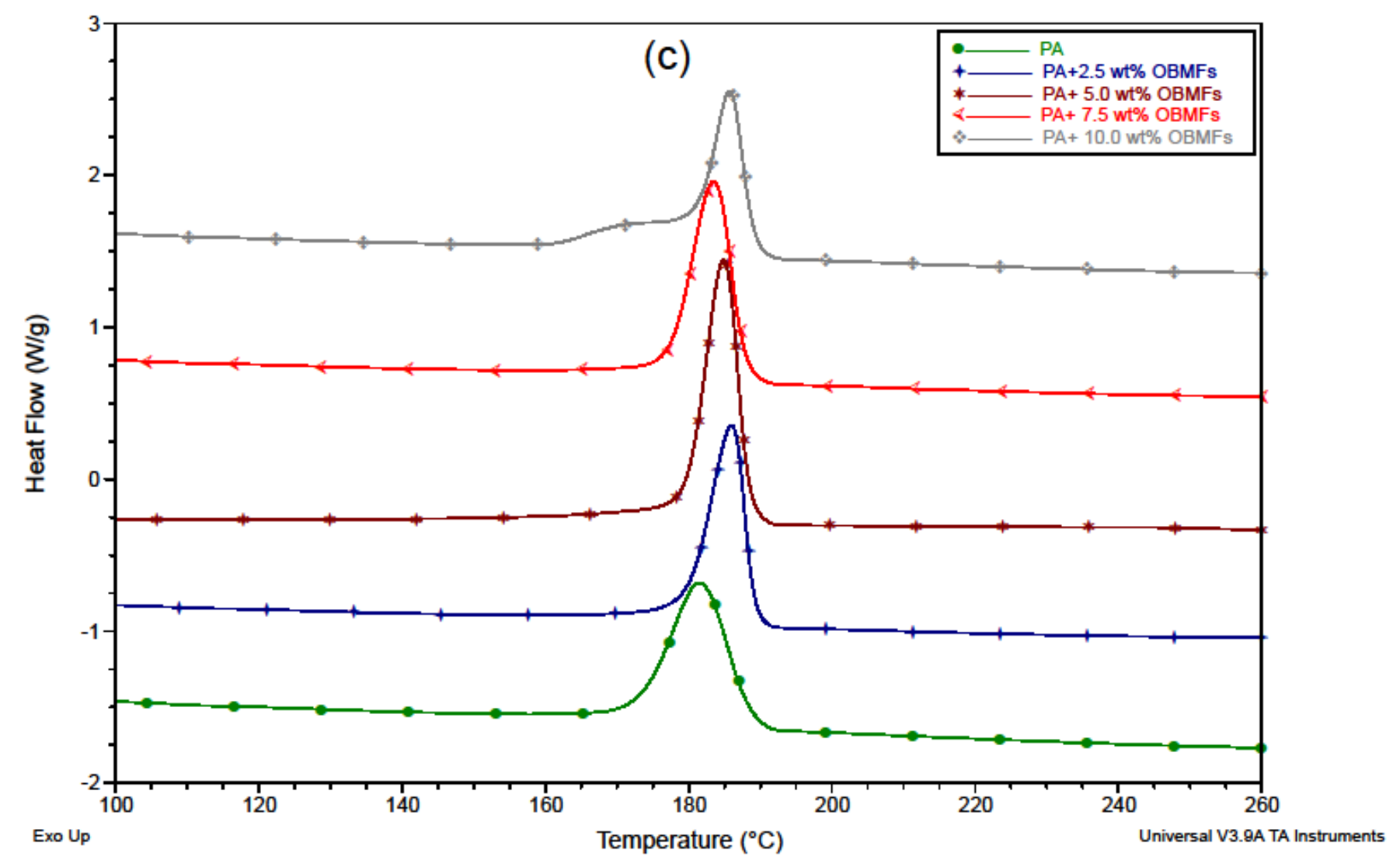

Fig. 6: DSC thermograms of PA6 and its nanocomposites at (a) $\mathrm{Tg}$; (b) $T_{m}$ and (c) $T_{c}$. 


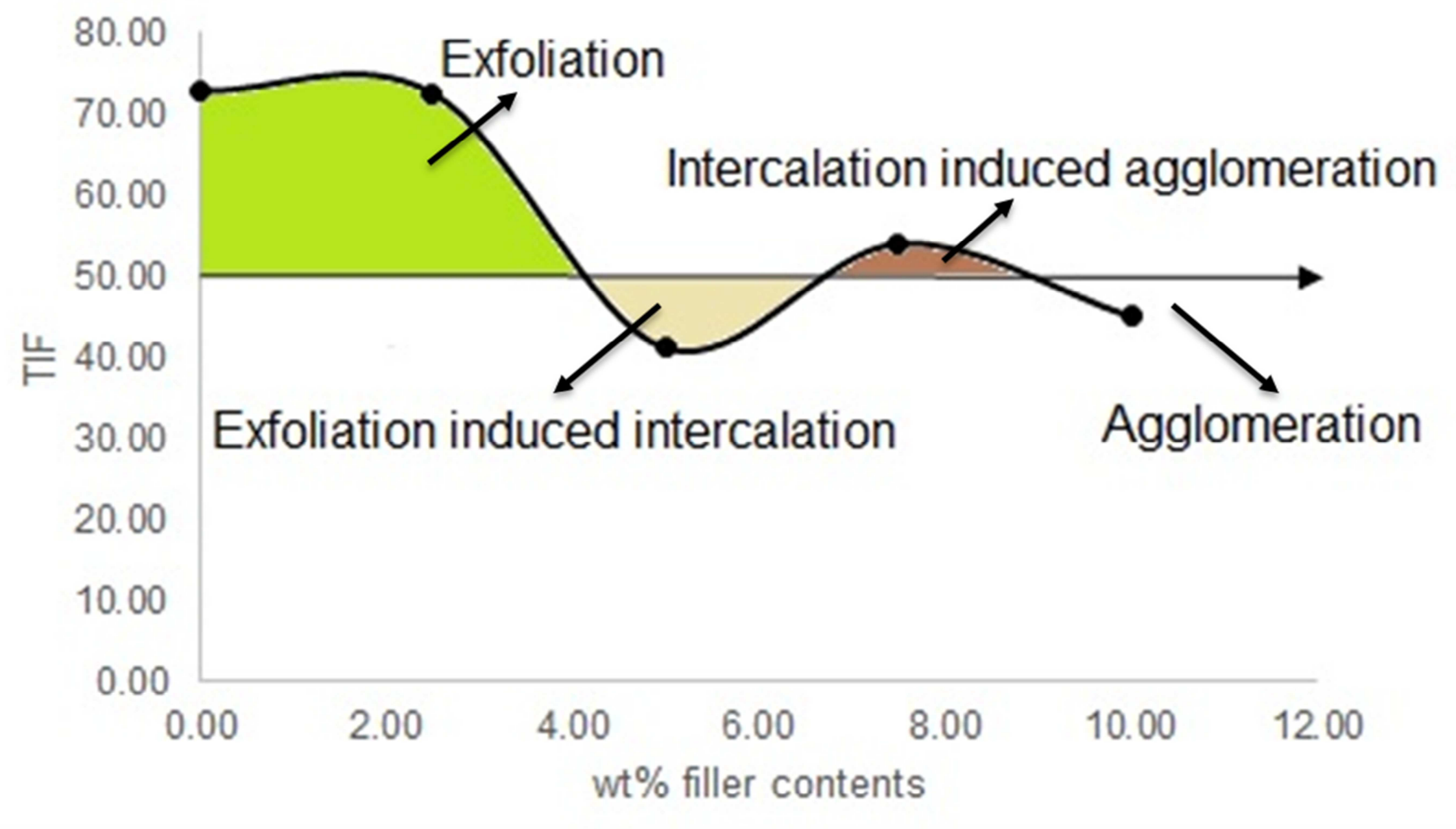

Fig. 7: Relation between TIF and dispersion behaviour of OBMFs in PA6 matrix. 


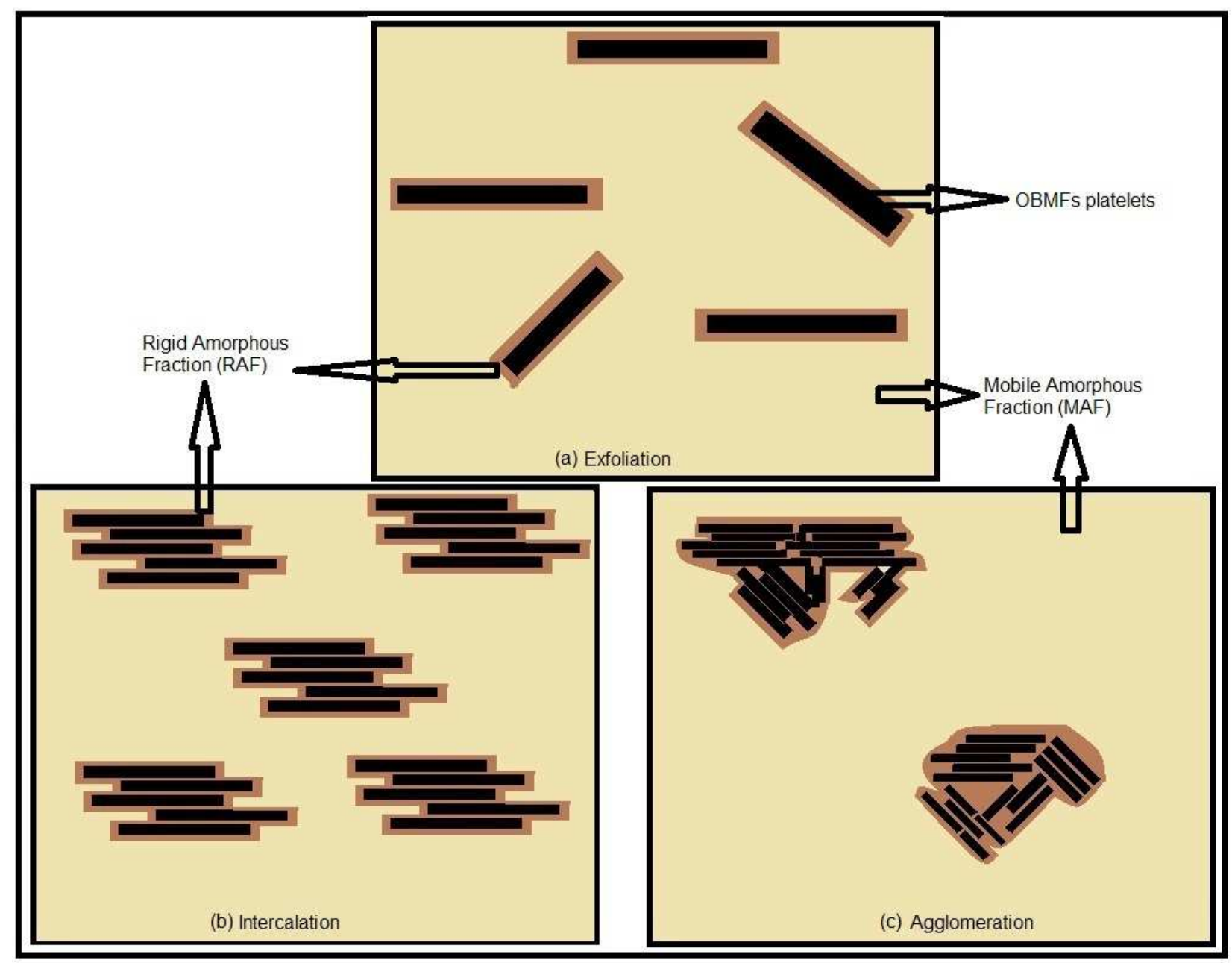

Fig. 8: Schematic diagram of OBMFs platelets associated with MAF and RIF of PA6 matrix. 


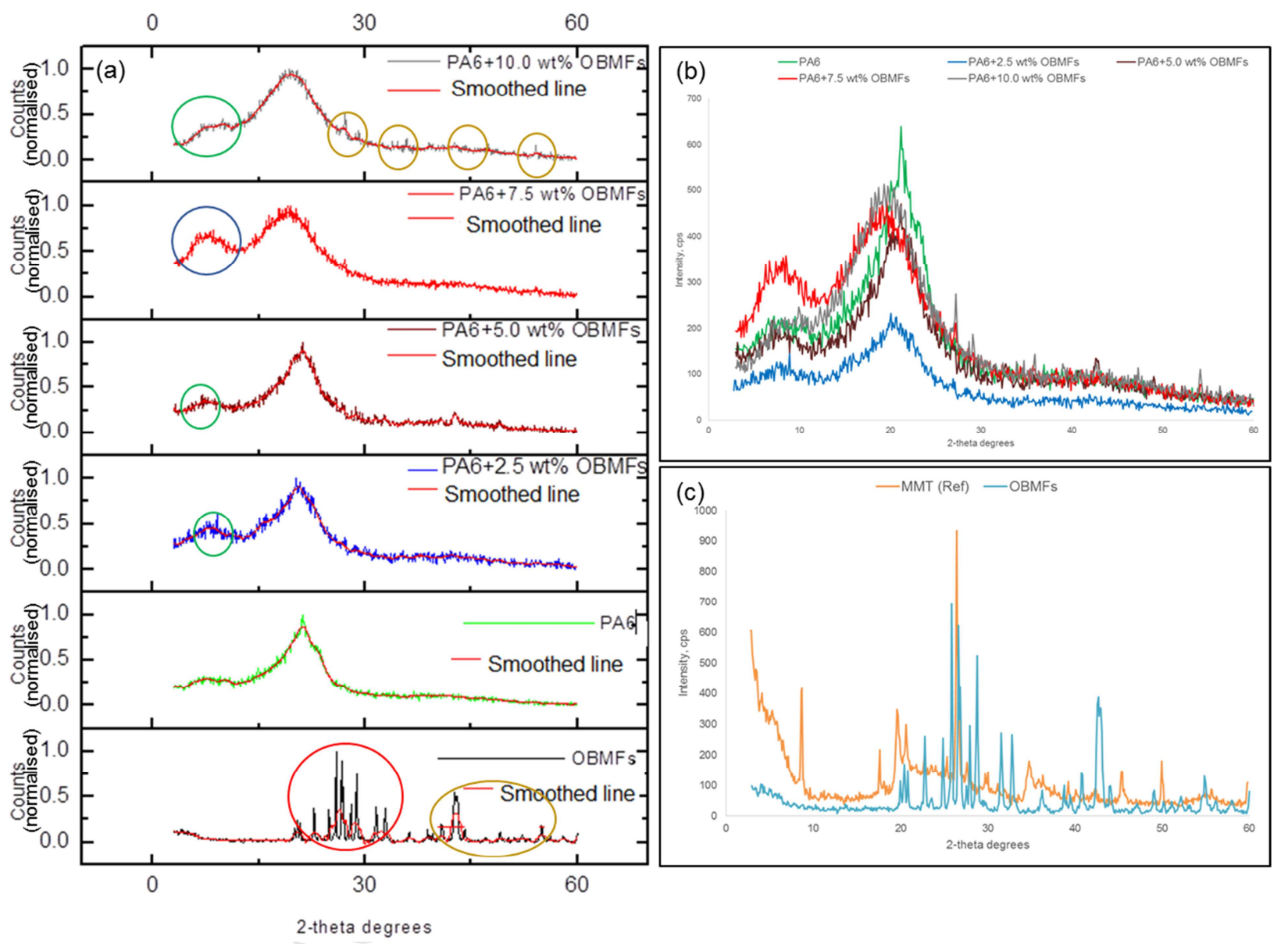

Fig. 9: WAXD patterns of (a) OBMFs and PA6/OBMFs nanocomposite in stack form; (b) nanocomposite in common scale; and (c) OBMFs and MMT. 

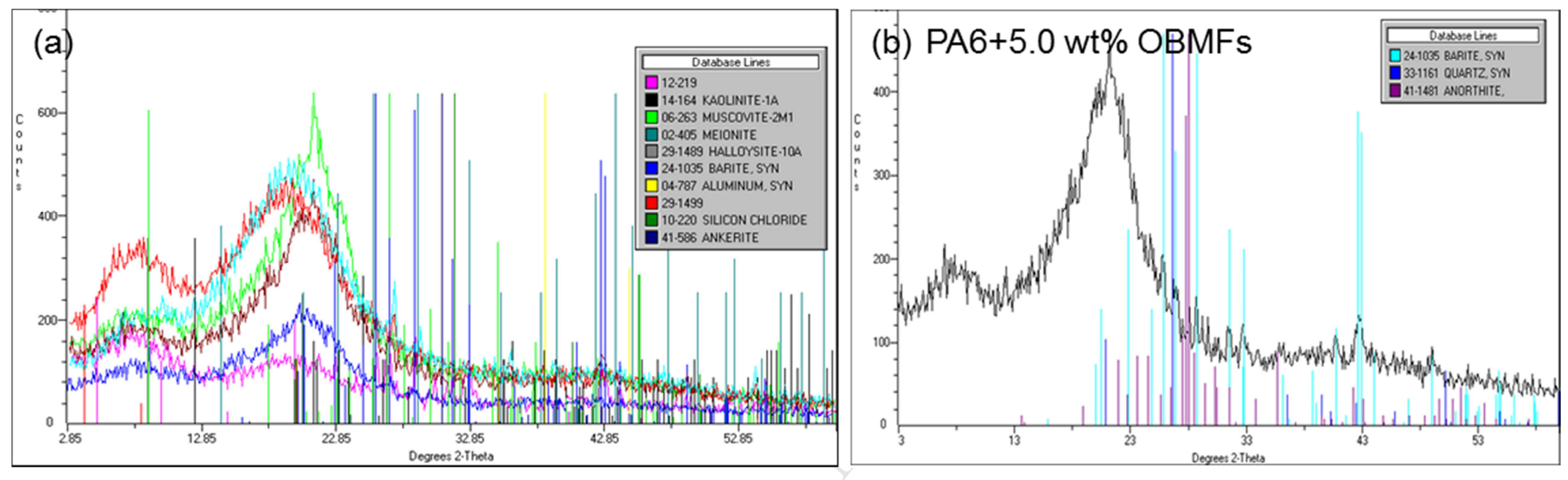

Fig. 10: WAXD patterns of (a) mineral composition of different nanocomposite; (b) new peaks identification in nanocomposites. 


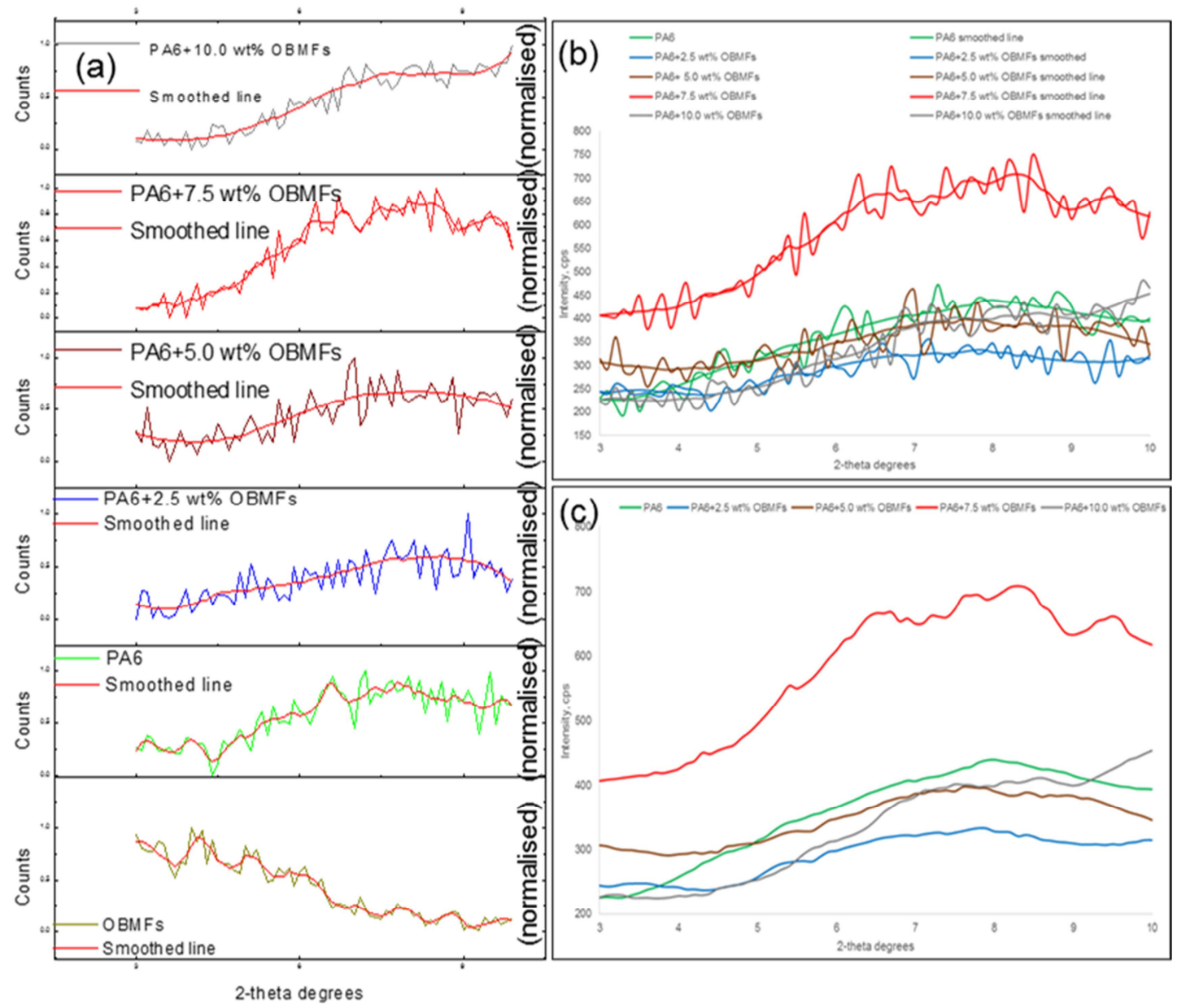

Fig. 11: SAXD patterns of (a) OBMFs and PA6/OBMFs nanocomposite in stack form; (b) nanocomposite in common scale; and (c) smoothed nanocomposite profile. 


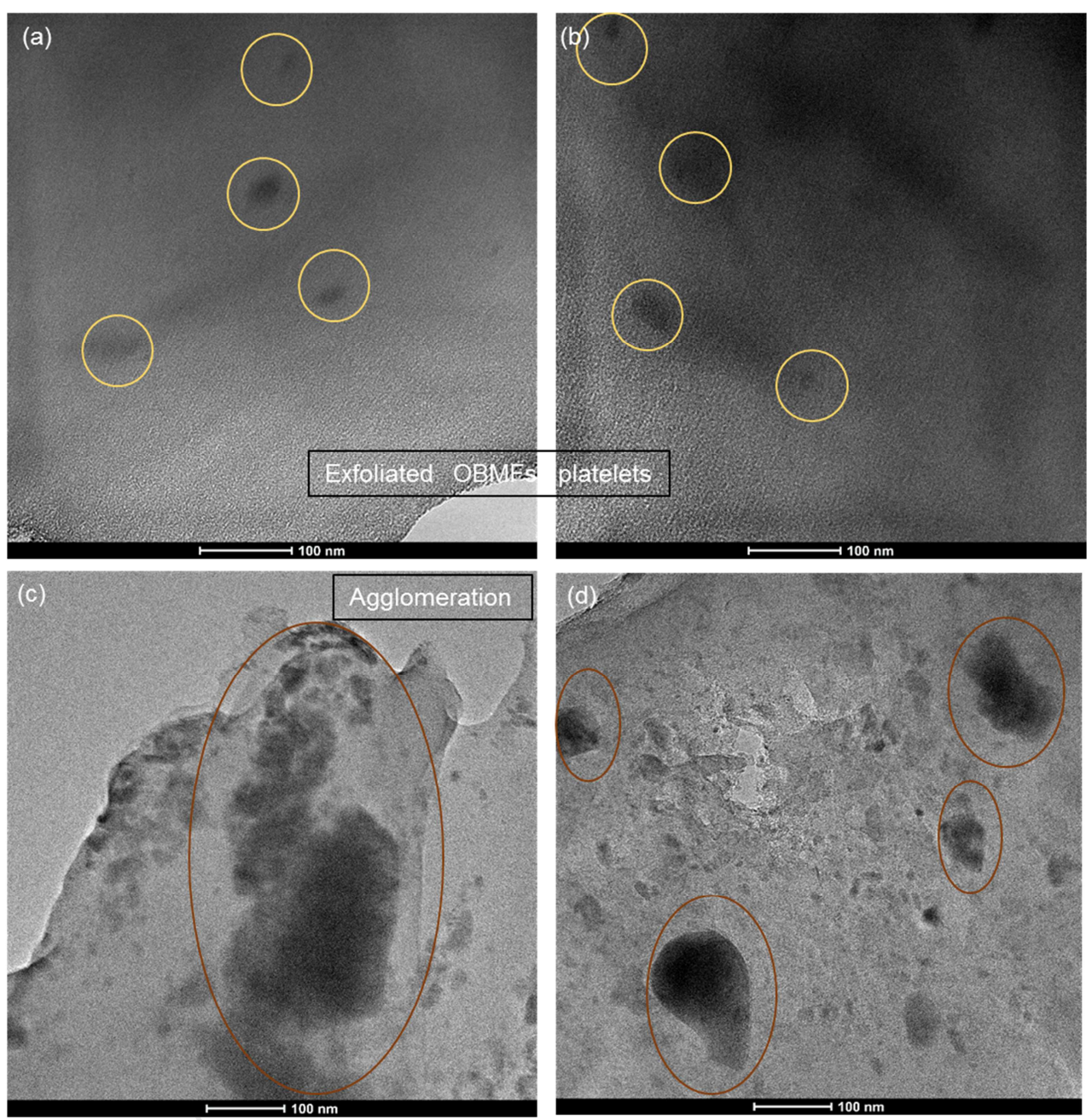

Fig. 12: TEM images of PA6 with 2.5 wt\% OBMFs nanocomposites (a) and (b) and PA6 with 10.0 wt\% OBMFs nanocomposites (c) and 
Table 1: ATR FT-IR peak assignments [20-23]

\begin{tabular}{cc}
\hline Wave $n$ umber $\left(\mathrm{cm}^{-1}\right)$ & Assignments \\
\hline 3295 & Hydrogen-bonded $\mathrm{N}-\mathrm{H}$ stretching \\
3079 & Fermi-resonance of $\mathrm{N}-\mathrm{H}$ stretching \\
2930 & $\mathrm{~V}_{\text {as }}\left(\mathrm{CH}_{2}\right)$ \\
2859 & $\mathrm{~V}_{\mathrm{s}}(\mathrm{CH})$ \\
1633 & $\mathrm{Amide} \mathrm{I}$ \\
1539 & Amide II \\
1462 & $\mathrm{CH}_{2}$ deformation \\
1435 & $\mathrm{CH}_{2}$ deformation \\
1370 & Amide III \& $\mathrm{CH}_{2}$ wag \\
1259 & Amide III \& $\mathrm{CH}_{2}$ wag \\
1200 & Amide III \& $\mathrm{CH}_{2}$ wag \\
1169 & CO-NH, skeletal motion $(\mathrm{Am})$ \\
1118 & $\mathrm{C}-\mathrm{C}$ stretching $(\mathrm{Am})$ \\
973 & $\mathrm{C}-\mathrm{C}$ stretch $(\mathrm{Am})$ \\
680 & $\mathrm{CO}-\mathrm{NH}$ in plane vibration \\
$525-580$ & Amide $\mathrm{V}$ \\
& Primary aliphatic nitriles $(\mathrm{C} \equiv \mathrm{N})$
\end{tabular}


Table 2: TGA analysis at different decomposition stages of PA6 and its nanocomposites with different clay loadings

\begin{tabular}{cccccc} 
Material & $\%$ wt loss at $250{ }^{\circ} \mathrm{C}$ & $\mathrm{T}_{\mathrm{D} 10 \%}\left({ }^{\circ} \mathrm{C}\right)$ & $\mathrm{T}_{\mathrm{D} 50 \%}\left({ }^{\circ} \mathrm{C}\right)$ & $\mathrm{D} 1 / 2 \mathrm{Time}$ & Residue $(\%$ wt $)$ at $600{ }^{\circ} \mathrm{C}$ \\
\hline PA6 & 3.37 & 399.24 & 431.42 & 40.82 & 0.00 \\
PA6+2.5 wt\% OBMFs & 2.93 & 407.77 & 442.23 & 41.61 & 2.03 \\
PA6+5.0 wt\% OBMFs & 2.87 & 416.87 & 446.21 & 42.42 & 6.79 \\
PA6+7.5 wt\% OBMFs & 3.19 & 412.32 & 439.38 & 41.35 & 7.59 \\
PA6+10.0 wt\% OBMFs & 2.65 & 416.87 & 447.35 & 42.27 & 6.09 \\
\hline
\end{tabular}

$\mathrm{T}_{\mathrm{D} 10 \%}$ : onset temperature of degradation at $10 \%$ weight loss and $\mathrm{T}_{\mathrm{D} 50 \%}$ : onset temperature of degradation at $50 \%$ weight loss.

Table 3: \% of crystallinity of PA6 and its nanocomposite using DSC

\begin{tabular}{ccccc}
\hline Material & $\Delta \mathrm{Hm}(\mathrm{J} / \mathrm{g})$ & $\Delta \mathrm{Hc}(\mathrm{J} / \mathrm{g})$ & $\Delta \mathrm{Hm}-\Delta \mathrm{Hc}(\mathrm{J} / \mathrm{g})$ & $((\Delta \mathrm{Hm}-\Delta \mathrm{Hc}) / \Delta \mathrm{Hm})^{\circ}{ }^{*} 100 \%$ \\
\hline PA6 & 52.83 & 0 & 52.83 & 22.96 \\
PA6+2.5 wt\% OBMFs & 48.05 & 0 & 48.05 & 20.88 \\
PA6+5.0 wt\% OBMFs & 49.32 & 0 & 49.32 & 21.43 \\
PA6+7.5 wt\% OBMFs & 51.56 & 0 & 51.56 & 22.41 \\
PA6+10.0 wt\% OBMFs & 50.73 & 0 & 50.73 & 22.05 \\
\hline
\end{tabular}


Table 4: Heat capacity of PA6 and its nanocomposite

\begin{tabular}{|c|c|c|c|}
\hline Material & Mass of samples $(\mathrm{m}) \mathrm{mg}$ & Heat capacity $(\mathrm{J} / \mathrm{g})$ & Specific heat capacity $(C p) \mathrm{Jk}^{-1} \mathrm{~kg}^{-1}$ \\
\hline PA6 & 6.20 & 60.57 & 2523 \\
\hline PA6+2.5 wt\% OBMFs & 6.30 & 55.87 & 2327 \\
\hline PA6+5.0 wt $\%$ OBMFs & 6.30 & 57.66 & 2402 \\
\hline PA6+10.0 wt $\%$ OBMFs & 6.30 & 64.69 & 1321 \\
\hline
\end{tabular}

Table 5: TIF determination using DSC

\begin{tabular}{ccccccc}
\hline Material & MAF & CF & CF' & RAF $=100-M A F-C F$ & RAF $^{\prime}=100-M A F-C F^{\prime}$ & TIF \\
\hline PA6 & 27.26 & 22.96 & 0.00 & 49.78 & 72.74 & 70.04 \\
PA6+2.5 wt\% OBMFs & 27.46 & 20.88 & 2.50 & 51.66 & 74 & 72.54 \\
PA6+5.0 wt\% OBMFs & 58.91 & 21.43 & 5.00 & 19.66 & 41.09 \\
PA6+7.5 wt\% OBMFs & 46.01 & 22.41 & 7.50 & 31.58 & 46.49 & 53.99 \\
PA6+10.0 wt\% OBMFs & 55.04 & 22.05 & 10.00 & 22.91 & 34.96 & 44.96 \\
\hline
\end{tabular}


Highlights:

- Reclaimed clay from oil based drilling fluid waste

- Demonstrates material tailorability for maximum heat resistant property, heat capacity and thermal stability

- Effect of OBMFs filler contents on dispersion behaviour

- Improvement in onset thermal degradation temperature

- Dispersion behaviour identification based on relation between TIF and MAF 